\title{
The Physics of Drought in the U.S. Central Great Plains ${ }^{\mathscr{D}}$
}

\author{
BEN LIVNEH \\ Cooperative Institute for Research in Environmental Science, and Department of Civil, Environmental, \\ and Architectural Engineering, University of Colorado Boulder, Boulder, Colorado \\ MARTIN P. HOERLING \\ NOAA/Earth System Research Laboratory, Physical Sciences Division, Boulder, Colorado
}

(Manuscript received 7 October 2015, in final form 20 June 2016)

\begin{abstract}
The semiarid U.S. Great Plains is prone to severe droughts having major consequences for agricultural production, livestock health, and river navigation. The recent 2012 event was accompanied by record deficits in precipitation and high temperatures during the May-August growing season. Here the physics of Great Plains drought are explored by addressing how meteorological drivers induce soil moisture deficits during the growing season. Land surface model (LSM) simulations driven by daily observed meteorological forcing from 1950 to 2013 compare favorably with satellite-derived terrestrial water anomalies and reproduce key features found in the U.S. Drought Monitor. Results from simulations by two LSMs reveal that precipitation was directly responsible for between $72 \%$ and $80 \%$ of the soil moisture depletion during 2012 , and likewise has accounted for the majority of Great Plains soil moisture variability since 1950. Energy balance considerations indicate that a large fraction of the growing season temperature variability is itself driven by precipitation, pointing toward an even larger net contribution of precipitation to soil moisture variability.

To assess robustness across a larger sample of drought events, daily meteorological output from 1050 years of climate simulations, representative of conditions in 1979-2013, are used to drive two LSMs. Growing season droughts, and low soil moisture conditions especially, are confirmed to result principally from rainfall deficits. Antecedent meteorological and soil moisture conditions are shown to affect growing season soil moisture, but their effects are secondary to forcing by contemporaneous rainfall deficits. This understanding of the physics of growing season droughts is used to comment on plausible Great Plains soil moisture changes in a warmer world.
\end{abstract}

\section{Introduction}

The occurrence of drought, broadly understood to be a condition of deficient moisture in the land surface (e.g., Wilhite 1987), is associated with agricultural loss, water resource shortfalls, and other economic impacts. The Great Plains is a region of national agricultural importance that experiences its rainy season (MayAugust) coincident with its growing season. Drought and climatic variability during this season can be far

Supplemental information related to this paper is available at the Journals Online website: http://dx.doi.org/10.1175/JCLI-D-150697.s1.

Corresponding author address: Ben Livneh, CIRES, University of Colorado Boulder, 216 UCB, Boulder, CO 80309.

E-mail: ben.livneh@colorado.edu reaching, as dryland (nonirrigated) farming is regionally common (Dhuyvetter et al. 1996). Cook et al. (2007) highlight that the climate of the Great Plains is transitional between the humid east and the arid west. Historically they note that this led to conflicting reports of the climate during early expansion of the western United States, as inhospitably arid (the "Great American Desert") or ideally humid for agriculture (the "garden myth"). In fact, the region has been prone to both extended wet and dry periods that have been identified using tree-ring chronologies in the paleo period (Woodhouse and Overpeck 1998; Cook et al. 2007). Even the last century includes notable droughts (e.g., 1930s and 1950s) as well as pluvial periods of abundant summer rainfall more recently (Wang et al. 2009).

Yet, despite a long history of drought over the Great Plains, identification and prediction of drought development remain a challenge (e.g., Schubert et al. 2008; 
Quan et al. 2012; Hoerling et al. 2014; Seager et al. 2014), which may explain expansive damages and losses that continue to accompany modern-era drought events (Luo and Wood 2007). The typical meteorological conditions associated with drought are well known, and include large precipitation deficits and high temperatures. Chang and Wallace (1987) make the point that drought and heat waves are related, in the sense that little rain tends to fall during heat waves, and that summer droughts are generally characterized by abnormally high surface air temperatures. Although these two phenomena generally possess different time scales-with drought usually lasting months and heat waves usually lasting days-they are coupled on monthly to seasonal time scales during which precipitation and surface temperature exhibit a strong inverse correlation, especially during summer over the central United States (e.g., Namias 1960; Madden and Williams 1978; Huang et al. 1996).

The inverse relationship between precipitation and temperature has been an important signature of recent droughts over Texas in 2011 (Hoerling et al. 2013; Seager and Hoerling 2014) and the 2012 central Great Plains drought (Hoerling et al. 2014; Seager et al. 2014). The general view from these and earlier case studies is that clouds and precipitation, through their effects on the surface energy balance, drive high temperature. Recently, Yin et al. (2014) tested whether high temperatures cause drought [through driving higher evapotranspiration (ET)], or whether the thermodynamic conditions were a consequence of drought [due to the inverse precipitation-temperature $(P-T)$ relationship], providing evidence that affirmed dominance of the latter process. However, a quantification of how each of these meteorological conditions drives soil moisture responses is still lacking. The importance of these land surface feedbacks and coupling with the atmosphere over the Great Plains has been highlighted in several studies (Georgakakos et al. 1995; Durre et al. 2000; Schubert et al. 2004; Basara et al. 2013). On a global scale, Seneviratne et al. (2010) presented a synthesis of soil moisture-climate interaction studies, focusing on both soil moisture-temperature and soil moisture-precipitation coupling, noting the former to be relevant for the occurrence of heat waves, particularly during conditions where soil moisture limits the total energy used by latent heat flux. They suggest that the relationship of higher precipitation leading to higher soil moisture can generally be considered trivial, although this relationship becomes skewed when precipitation rates are extremely high or low. Importantly, their study, along with nearly all other drought analyses, stops short of explicitly quantifying the relationship between temperature and precipitation during drought, something we recognize will be regional in nature, and which motivates the present study of the Great Plains.

The question thus remains open about the physics of land surface moisture deficits during drought. In this study, we explore the relationships among temperature, precipitation, and soil moisture deficits over the central Great Plains with the goal of providing insights into the associative nature of these quantities in drought development. The purpose of our analysis is to quantify the proximal meteorological causes for drought over the Great Plains, with a focus on the 2012 event. The study builds upon previous investigations that conducted an attribution of the causes for the meteorological conditions during summer 2012 (Hoerling et al. 2014), or regional drought drivers more generally (Basara et al. 2013).

Here we utilize land surface models (LSMs) to diagnose physical causes for the soil moisture deficits that were the immediate drivers for the unprecedented agricultural losses that occurred that summer (Hoerling et al. 2014). LSMs have been applied to model drought, typically relying on simulated soil moisture deficits-driven by observed meteorology-to characterize drought severity. Comparison between the Variable Infiltration Capacity (VIC) model (Liang et al. 1994), an LSM, and the Palmer drought severity index (PDSI; Palmer 1965) generally show good correspondence (Sheffield and Wood 2008). Vicente-Serrano et al. (2015) compare various meteorological indices of drought and find low sensitivity of the PDSI to potential evapotranspiration (PET) compared to other indices. They thus advise against the application of PDSI as a drought index in semiarid regions where PET is dominant.

Comparison of drought characterization among LSMs [e.g., VIC, the Noah LSM (Ek et al. 2003), and the North American Regional Reanalysis (NARR; Mesinger et al. 2004)] also reveals intermodel differences, especially in their formulation of ET (Sheffield et al. 2012). A further uncertainty concerning drought simulations using LSMs is their dependence upon assumptions about the land surface (e.g., soil texture, depth) and the myriad physical process representations. However, these drawbacks are outweighed by the essential features of LSMs, namely explicit closure of water and energy balances, enabling a mechanistic accounting for drought processes in time and across space. To incorporate these model structural uncertainties in our appraisal of the physics of drought, two LSMs are employed. Importantly, this multimodel approach with each LSM identically forced by prescribed meteorology enables a clearer assessment of drought drivers than in many past studies (e.g., Cook et al. 2014, 2015; Seager et al. 2007, 2013; Dai 2013; Fu and Feng 2014; Scheff and Frierson 2015) that analyze 
outputs from an ensemble of Coupled Model Intercomparison Project (CMIP) models. The latter approach confounds interpretation of robust physics because both land surface model and meteorological drivers are different among each CMIP model. Two other unique features of this study are 1) decomposition of the influences of precipitation and temperature on Great Plains soil moisture deficit and 2) quantifying the predictability of growing-season soil moisture using both antecedent moisture and El Niño-Southern Oscillation (ENSO) phase as predictors.

Section 2 describes the historical observations, experimental methods, and LSM simulations. Also described are the historical climate simulations for which the physics of drought events are also diagnosed so as to build upon the observationally based analyses. Section 3 presents diagnosis of the 2012 observed Great Plains drought, as well as a diagnosis of climate model-generated droughts. A summary of results is given in section 4, where we also discuss how understanding the physics of growing season Great Plains drought pertains to our interpretation of how the region's soil moisture may change in a warmer world.

\section{Data and methods}

The experiments conducted use both observed and simulated meteorology to drive LSMs to explore the influences of precipitation, temperature, and antecedent moisture conditions on drought in the Great Plains. LSMs are superior for such analysis over simpler drought indices [e.g., PDSI or the standardized precipitation evapotranspiration index (SPEI)] because they close both water and energy balances and provide physically based representations of important storages and fluxes of water within the land surface. Although cold-season processes are not discussed in this analysis, their physics are included within all LSMs and GCMs described below.

\section{a. Observations}

The gridded historical observational dataset of Livneh et al. (2015) is used to characterize observed daily meteorology. The data span the period 1950-2013 and include station-based daily precipitation and daily maximum and minimum temperature. Also, daily wind speed is included, based on the NCEP-NCAR reanalysis. Gridding is to a $1 / 16^{\circ}(\sim 6 \mathrm{~km})$ spatial resolution. For purposes of intercomparison with GCM scales, the observed data are aggregated to a $0.5^{\circ}(\sim 50 \mathrm{~km})$ resolution.

Estimates of drought can be skewed by uncertainty of model input data (Williams et al. 2015), especially the choice of precipitation dataset (Trenberth et al. 2014). To provide an estimate of uncertainty in precipitation forcing, Livneh et al. (2015) compared their product against two others: 1) the North American Land Data Assimilation System phase 2 (NLDAS2; Xia et al. 2012) for the common period of 1979-2013 and 2) the Climatic Research Unit (CRU v.3.22; Harris et al. 2014) for the common period 1950-2013, with comparatively small differences among products over the Great Plains relative to other parts of North America. The Livneh et al. (2015) product is on annual average approximately $7.5 \mathrm{~mm}(\sim 1.1 \%)$ wetter than NLDAS2 and $10.7 \mathrm{~mm}$ ( $\sim 1.5 \%$ ) wetter than CRU over the study domain based on a mean annual precipitation of $720 \mathrm{~mm}$.

Daily climatological values were required to drive the LSMs for the synthetic experiments described below. Minimum and maximum temperature climatologies were computed as the simple long-term mean. For precipitation, a more sophisticated two-step approach was applied to avoid climatological "drizzle" that would result from simple averaging, as well as to preserve spatially coherent precipitation patterns. The procedure was as follows. For each of the 12 months and for each grid point, the mean monthly precipitation and the average number of "wet" days (using a 1-mm threshold) were calculated. Next, a search was conducted among the same month historically (1950-2013) to find an analog month with the closest match to the mean monthly wet days. Matching wet days was done in order to ensure realistic spatial coherence of precipitation events. Last, the daily values in this analog month were scaled to match the long-term monthly mean precipitation for that month. These 12 climatologicalanalog months were repeated (1950-2013) to drive model simulations.

\section{b. Land surface models}

Simulations of historical soil moisture were made using the VIC macroscale hydrologic model. VIC is a physically based, fully distributed water and energy balance model that has been successfully applied to simulate drought both nationally and globally (e.g., Sheffield and Wood 2008; Sheffield et al. 2012). A full description appears in the appendix.

An updated version of the Unified Land Model (ULM; Livneh et al. 2011) was included for the historical observed simulations. This model contains physics largely independent of VIC and as such provides an independent estimate of hydrologic sensitivity. Details of ULM and model updates are provided in the appendix. ULM and VIC were both driven with the Livneh et al. (2015) forcing data for the full period, 1950-2013. 

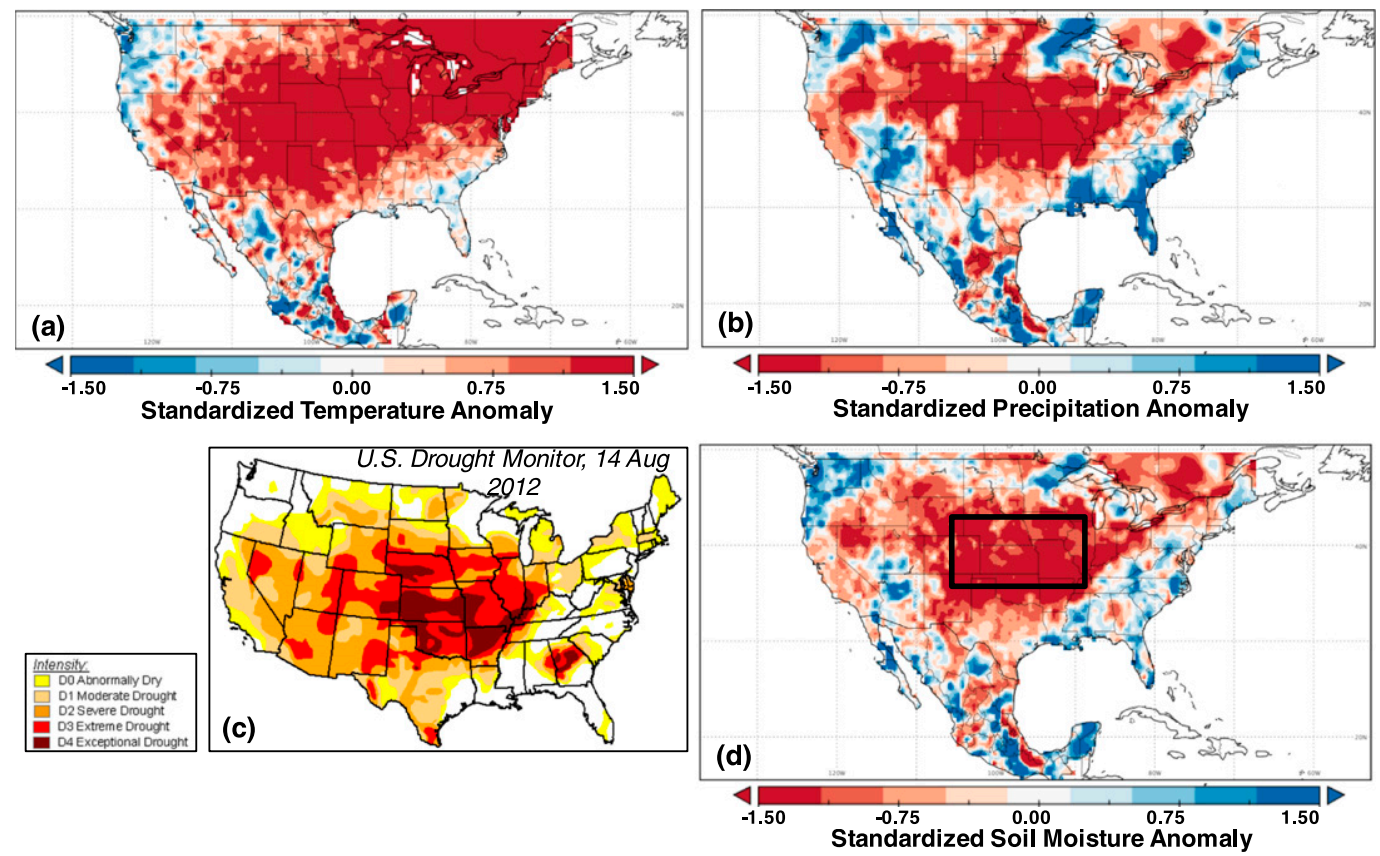

FIG. 1. Depiction of standardized August 2012 (a) temperature and (b) precipitation anomalies relative to a 1981-2010 reference period, as well as (d) VIC simulated soil moisture anomalies (top $1 \mathrm{~m}$ of soil) showing the extents of the study domain $\left(36^{\circ}-43^{\circ} \mathrm{N} ; 90^{\circ}-105^{\circ} \mathrm{W}\right)$ compared with (c) the USDM, which is based on discrete severity classes D0-D4 shown in the inset, determined based on five key indicators: 1) PDSI, 2) NOAA/Climate Prediction Center (CPC) simulated soil moisture, 3) U.S. Geological Survey (USGS) weekly streamflow percentiles, 4) SPI, and 5) objective short and long-term drought indicator blends (percentiles); additionally, numerous supplementary indicators including drought impacts and local reports from more than 350 expert observers around the country-hence the drought severities are comparable to VIC only in a qualitative sense.

\section{c. Climate model simulations}

Climate simulations are based on ECHAM5 (Roeckner et al. 2003), which was run at spectral T156 $\left(\sim 0.75^{\circ}\right)$ resolution with 25 vertical levels in the troposphere. These fully forced Atmospheric Model Intercomparison Project (AMIP) experiments impose specified observed monthly varying sea surface temperatures (SSTs), sea ice concentrations (SICs), and greenhouse gas concentrations from January 1979 to December 2013. A 30-member ensemble of simulations was performed, in which each simulation was subjected to the same time-evolving boundary forcing, but begun from different atmospheric initial conditions. The ensemble runs therefore represent a 1050-yr realization of current climate conditions (1979-2013). Further details of these experiments are provided in Seager and Hoerling (2014).

The daily meteorological fields of the GCM simulation are used to drive VIC (called VIC-GCM), yielding a 1050-yr-long LSM experiment from which we extract severe drought occurrences for further study. Severe drought cases are based on the sample of the lowest first percentile of simulated May-August Great Plains rainfall. A systematic intercomparison of VIC-GCM and the
GCM's land surface responses is conducted to address robustness, and the general features of antecedent and concurrent meteorological and soil moisture conditions are subsequently identified.

\section{Results}

\section{a. Baseline historical drought simulations}

The historical LSM simulation, spanning 1950-2013, was carried out with observed meteorology to isolate the contributions of precipitation and temperature on soil moisture deficits. Figure 1 presents results for the recent 2012 drought event, which we will refer to as our baseline case for understanding the physics of drought. This simulation is evaluated against two independent estimates of soil moisture deficits during the 2012 event: the U.S. Drought Monitor (USDM) and the terrestrial water anomalies of the Gravity Recovery and Climate Experiment (GRACE) satellites.

Figure 1d shows the August 2012 VIC soil moisture deficit for a 1-m soil layer (encompassing most vegetation roots) and compares those to the August 2012 temperature (Fig. 1a) and precipitation (Fig. 1b) 


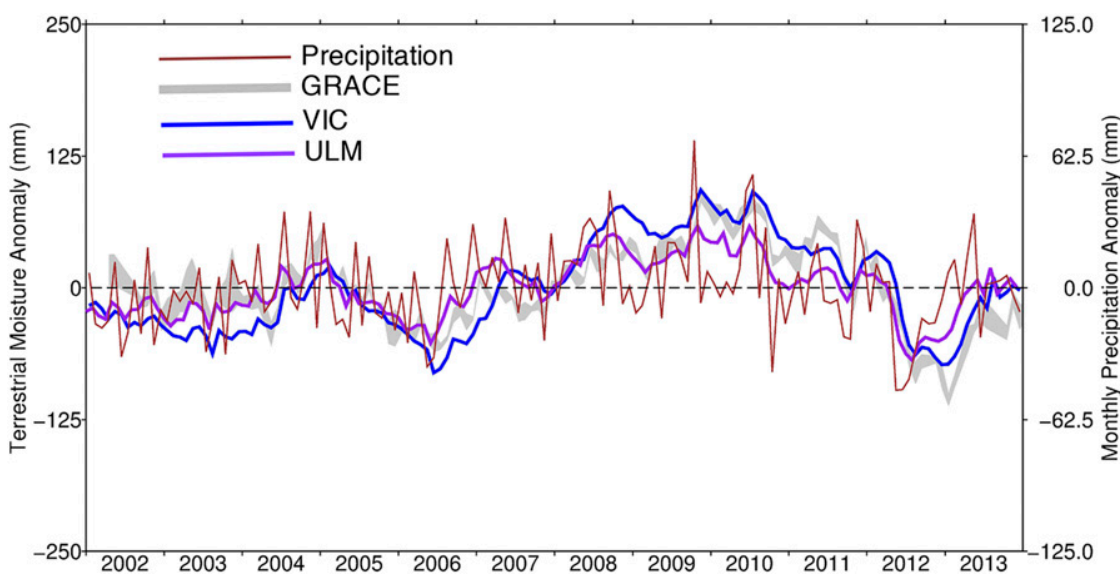

FIG. 2. Monthly anomalies (2002-13) for observed precipitation (on the right ordinate) and GRACE, ULM, and VIC terrestrial water anomalies (on the left ordinate) averaged over the Great Plains domain.

anomalies. All fields are standardized to their respective 1981-2010 climatologies. VIC simulates widespread soil moisture deficits exceeding one standard deviation across nearly all of the central United States, an area of maximum precipitation deficits and elevated surface temperatures having comparable standardized departures. VIC soil moisture matches the main features of the USDM to first order, including large soil moisture deficits over the assessed 2012 extreme event, to exceptional drought regions from Nebraska to Oklahoma. For the continental United States as a whole, VIC and the USDM are in excellent agreement, with both indicating that the extreme drought in the midsection of the continent is enveloped by normal soil moisture conditions in the Pacific Northwest and the Southeast.

To further assess robustness and representativeness of the VIC soil moisture simulation, a 2002-13 time series for the area averages of the central Great Plains box of Fig. 1d are constructed. Three soil moisture products are compared through time in Fig. 2, including simulations from VIC and ULM - each driven by identical observed meteorology - as well as the remotely sensed estimate of terrestrial water anomalies from GRACE, compared alongside the gridded precipitation measurements. A key result is confirmation of the realism in VIC's simulated soil moisture variability by the wholly independent GRACE estimated land moisture variability. The ULM standardized soil moisture anomalies provide a measure of structural uncertainty that arise from different model physics. These track VIC (and GRACE) closely and, despite several missing months in the GRACE data, the simulated monthly anomalies exhibit a temporal correlation of 0.86 and 0.85 during 2002-13 for VIC and ULM, respectively. The ULM exhibits a slightly smaller overall sensitivity than VIC, as indicated by its lower interannual variability, with simulated monthly standard deviations of $27.6 \mathrm{~mm}$ month $^{-1}$ (ULM) and $44.4 \mathrm{~mm}$ month $^{-1}$ (VIC) encapsulating the GRACE variability $\left(37.9 \mathrm{~mm} \mathrm{month}^{-1}\right)$.

Several features of the Great Plains 2012 drought event set it aside from other dry periods during 2002-13. First, soil moisture conditions in 2012 (by almost all indicators) experienced their most severe deficits. The event was characterized by a rapid onset, apparently associated with a marked drop in precipitation in late spring 2012, although it is worth noting the lag between precipitation and soil moisture deficits. Also, although not shown in Fig. 2, we note that spring 2012 surface temperatures were record-setting over the Great Plains and that this condition may also have contributed to sudden drought onset, as will be analyzed subsequently. Another salient feature of the 2012 event was a general abundance of land surface moisture that preceded the 2012 summer drought (2007-11 was a prolonged moist period). Finally, 2012 can be contrasted with the 2006 drought, which was preceded by a multiyear dry state. Thus, this time series raises several questions about the relationship between antecedent moisture and subsequent meteorological conditions with drought during May-August 2012.

A longer historical context since 1950 reveals that the 2012 summer drought, while experiencing extreme seasonal temperature and precipitation departures, did not experience commensurate extreme soil moisture departures. We interpret this difference in meteorological drivers and land surface conditions to reflect the importance of antecedent conditions, since unlike 1956, which was the most severe simulated soil moisture deficit and was preceded by three dry years, 2012 was preceded by neutral moisture conditions. This is indicated by the 

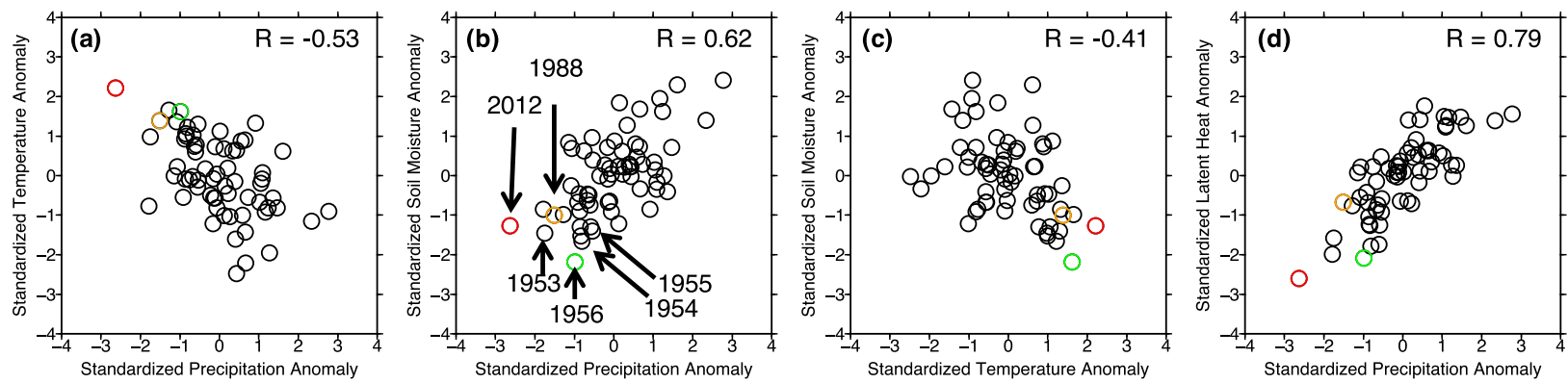

FIG. 3. Seasonal (MJJA) temperature, precipitation, and VIC-simulated soil moisture and latent heat flux (1950-2013) expressed as standardized anomalies (1981-2010 reference period) for the Great Plains domain. Note the 2012 drought (red), a severe drought in recent memory (1988; orange), as well as the most severe soil moisture deficits during this period (1956; green), which occurred after three consecutive years of very dry conditions, highlighting the contributions of antecedent conditions for the most intense droughts.

scatter relations on Fig. 3, which show each year's mean May-August (MJJA) conditions (1950-2013). Note especially that the summer temperature and precipitation departures in 2012 were each appreciably greater than during any prior summer (Fig. 3a). The extreme temperatures of 2012 are consistent with the extreme rainfall deficits through the physical driving of the former by the latter, as revealed by the historical inverse relationship between the two variables $(R=-0.53)$. The possibility of nonstationarity in these variables cannot be discounted, although neither temperature nor rainfall exhibits appreciable trends during summer over this region.

This combined $P-T$ severity in 2012 forms the basis for asking how much the lack of precipitation and the high surface temperatures each contributed to drought severity in 2012, as indicated by their contributions to soil moisture depletion. A useful heuristic framework for exploring this issue is to consider the magnitude of the sensible to latent surface flux, known as the Bowen ratio $B$ :

$$
B=\frac{\mathrm{SH}}{\mathrm{LH}},
$$

where $\mathrm{SH}$ is the sensible heat flux and LH is the latent heat flux, terms that are analyzed in more quantitative manners in the subsequent section. Suffice it here to simply note that an important effect of prolonged precipitation deficits is to reduce surface moisture and the associated upward turbulent flux of latent energy, which is compensated for by an increased SH (i.e., surface warming). Figure $3 \mathrm{~b}$ shows the clear relationship between precipitation and soil moisture $(R=0.62)$, and an even tighter relationship between LH and $P(R=0.79)$ in Fig. 3d. As a consequence, in the absence of rainfall and thus a reduction in surface moisture, a greater fraction of incoming solar radiation is balanced by increased upward turbulent $\mathrm{SH}$, thereby leading to high surface temperatures. This link is illustrated by the relationship between soil moisture and surface temperature in Fig. $3 \mathrm{c}(R=-0.41)$. While these are useful qualitative perspectives on why droughts and heat waves are often coincident, they do not indicate the magnitude of the soil moisture deficits that occur during droughts owing to high temperatures, or for that matter whether high temperatures alone can drive drought conditions of the magnitude witnessed during historical events.

Historical Great Plains droughts provide an interesting counterpoint to the event in 2012. Note especially that, based on the VIC simulations, the summer of 1956 likely experienced the most severe summertime soil moisture deficits over the last 64 -yr period, nearly double the severity of the soil moisture deficits of the 2012 event (cf. red and green circles in Fig. 3b). This despite the fact that summer 2012 was hotter and experienced greater rainfall deficits. The analysis reveals the important role of antecedent conditions. In particular, 1956 was the last year in a string of dry years over the Great Plains that rivaled the Dust Bowl period in some areas, whereas the 2012 case was preceded by relatively moist period as detailed above. Figure 4 illustrates the VIC simulated time-depth soil moisture contour for the period during January-December 2012. Note that the soil deeper than $1 \mathrm{~m}$ was relatively moist through April 2012. An unusually hot spring appeared to contribute to modest drying in the near-skin layers during spring. However, the principal drying in the upper layer occurs rapidly in May, the first month of failed rains, with a much more muted response below 1-m depth. Indeed, the VIC simulations indicate that the deep layer did not become abnormally dry until July, at which time the top layer soil moisture had already achieved an anomaly of greater than -2 standardized departures. Overall, soil drying progresses from shallow layers to deeper (ULM qualitatively similar, not shown). The surface and deepest soil layers are out of phase by several months, whereby surface soil moisture largely 


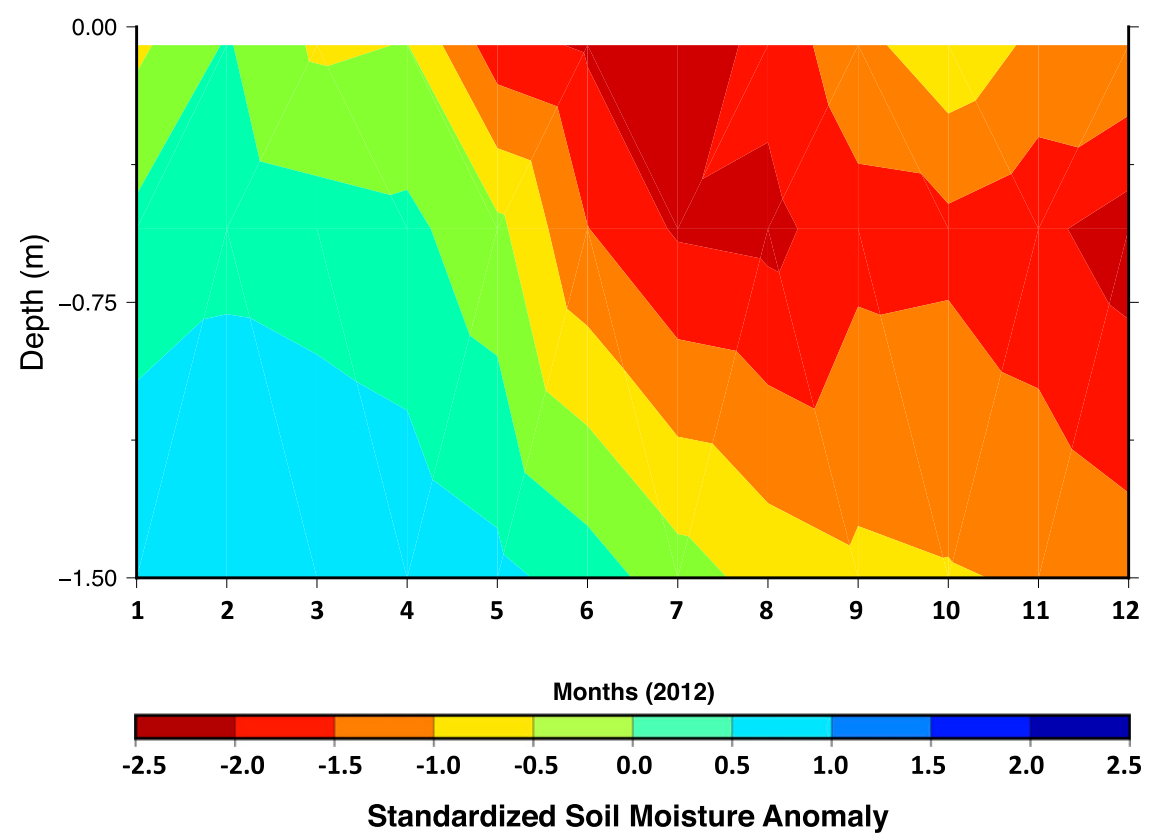

FIG. 4. Monthly profiles of VIC standardized soil moisture anomalies during 2012 computed relative to 1981-2010 reference; nodes are calculated as the mean depth of each model soil layer where VIC has three layers. The transition from left to right portrays the soil drying progressing from shallower to deeper layers.

recovers by the end of 2012 , while the deepest layer becomes progressively drier carrying the memory of the summer drought into the following winter.

\section{b. Sensitivity experiments isolating temperature and precipitation impacts on drought}

To quantify the role of precipitation and temperature in drought severity, two synthetic simulations are run in which either precipitation or temperature is set to climatological values while the other variable fluctuates as observed. The resulting soil moisture anomalies from each experiment are compared against the baseline simulation. The monthly evolving soil moisture, expressed in standardized anomalies, is examined for the 2012 drought event in Fig. 5. The key results regarding meteorological driving of the 2012 drought are as follows: 1) the majority of soil deficits are driven by precipitation, 2) the simulated soil moisture deficits are not extreme for any single month (approximately -1.5 standardized departures) even though precipitation deficits were a historical record (approximately -2.5 standardized departures), and 3) initial soil moisture at 1 May 2012 was near normal, and not unduly depleted as might have been surmised from the record setting hot spring (Dole et al. 2014), although we note the depth dependency of these influences as suggested in Fig. 4.

Figure 6 presents the simulated soil moisture anomalies for August 2012. A visual comparison between
Figs. 1a and 1b and Fig. 1d confirms the control of precipitation on soil moisture conditions during the 2012 drought. The baseline simulation yielded an $\mathrm{Au}-$ gust 2012 Great Plains soil moisture anomaly of -1.50 standardized departures, while the precipitation-only simulation yields -1.21 and the temperature-only simulation yields -0.46 standardized departures, respectively. The superposition of the anomalies from the two synthetic cases slightly exceeds the baseline (1.67 > 1.50 ), suggesting nonlinearity, with the same disparity observed for the MJJA period. Overall, the results indicate an approximately 2.5:1 ratio of precipitation relative to temperature in terms of contribution to total column soil deficits in $2012(2.63: 1=72.5 \%)$. This experiment was repeated with ULM confirming a precipitation dominance, albeit even to a greater degree, exhibiting a smaller anomaly for the baseline (1.44 standardized anomalies) with precipitation and temperature contributions at an approximate $4: 1$ ratio, respectively $(4.11: 1=80.4 \%)$.

Recalling that temperature and precipitation are strongly (inversely) correlated over the Great Plains in summer (see Fig. 3), with temperature being principally (although not exclusively) a response variable to precipitation driving of the surface energy balance, the inference of the role of precipitation in drought generation is likely understated in the above synthetic experiments for the 2012 event. To quantify this effect, an additional 


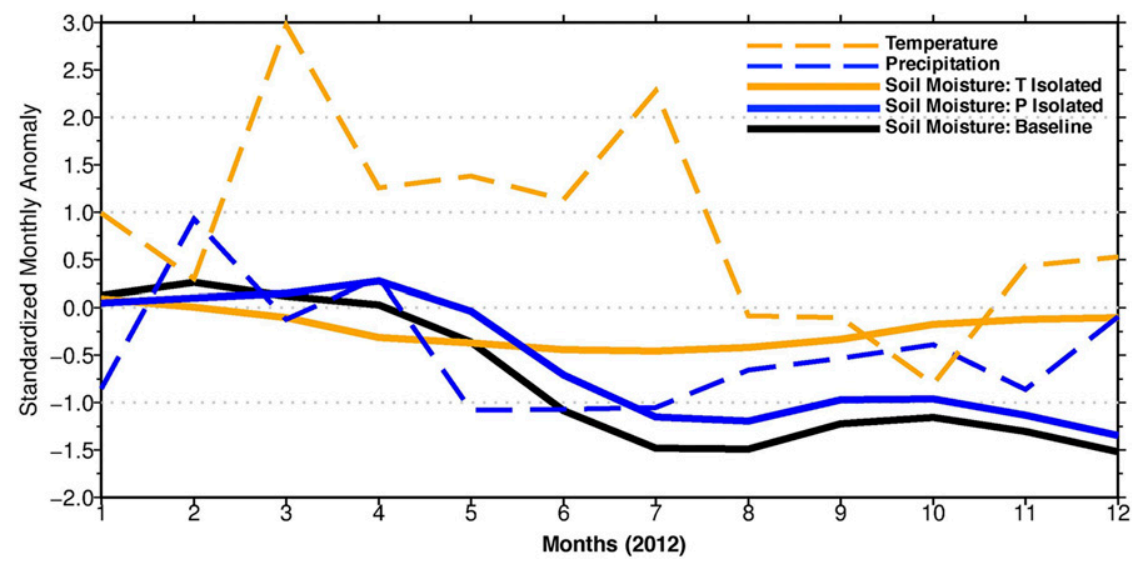

FIG. 5. Monthly standardized anomalies (1981-2010 reference) for observed precipitation (blue dashed) and temperature (orange dashed) for 2012, with baseline VIC simulations using observed meteorology in black, with precipitation impacts isolated through driving VIC with temperature climatology (solid blue) and temperature impacts isolated using precipitation climatology (solid orange) also shown.

simulation was performed in which the monthly varying regression of temperature on precipitation variability was removed from the raw temperature time series at each point. This residual temperature data were then used to drive a new synthetic simulation, the results of which (not shown) indicated that roughly half of the temperature impact indicated in Fig. $6 \mathrm{~b}$ is itself symptomatic of precipitation driving.

For both of the above cases, it is important to note that standardized anomalies were chosen for convenience in presenting and comparing among different fields. Yet, our calculations indicate that soil moisture becomes non-Gaussian for the months July-December according to the Shapiro-Wilkes test $(p=0.05)$, having a positive skew in these months. The positive skew has the effect of compressing negative standardized anomalies, making them appear less severe than reality. We explore this further below by showing soil moisture percentiles in addition to standardized anomalies as the former are insensitive to skew or assumed distributions.

\section{c. General characteristics of Great Plains droughts}

Our analysis of the 2012 event raises a variety of questions about the physics of Great Plains drought and the generality of those findings concerning the relation of precipitation, temperature, and soil moisture. For instance, what is the sequence of meteorological conditions that typically leads to extreme soil moisture depletion and hence to more severe droughts? Does the relationship between soil moisture and meteorological conditions change for more extreme droughts compared to milder droughts? And, from a perspective of anticipating drought, what is the inherent memory of soil moisture and are there antecedent conditions that render Great Plains drought predictable?

These questions are not addressable from the historical observations alone, for which too few samples of severe drought exist. The paper therefore turns to coupled atmosphere-land climate simulations using a large ensemble of historical AMIP-style experiments. We examine a collection of severe drought events drawn from the available 1050 years of model simulations, and stratify those by various indices of precipitation deficits and high temperature to explore soil moisture depletion behavior. Figure 7 assesses the quality of the ECHAM5 annual cycle of precipitation (top) and surface temperature (bottom). The model reproduces the distinct spring-early summer wet season, having a May maximum as observed. Overall, the model's average May-August rainfall is about $15 \%$ less than observed, although the observed monthly values reside within the sampling variability. Surface temperatures are warmer than observed, and during summer are roughly $1^{\circ}-2^{\circ} \mathrm{C}$ warmer than observed, a bias that is inconsistent with sampling error.

With a principal goal to diagnose the land surface sensitivity to meteorological forcing, we use the GCM soil moisture directly based on its land model, and also conduct a parallel offline VIC simulation (VIC-GCM) driven by the GCM's meteorology. Figure 8 diagnoses the long-term memory of soil moisture anomalies (after removing the seasonal cycle), demonstrating the consistency among the LSMs of ECHAM5, VIC-GCM, and the observed-meteorology-driven VIC simulations. Within the uncertainty of sampling, the autocorrelation drops to 0.5 between months 5 and 6 ; however, each case 


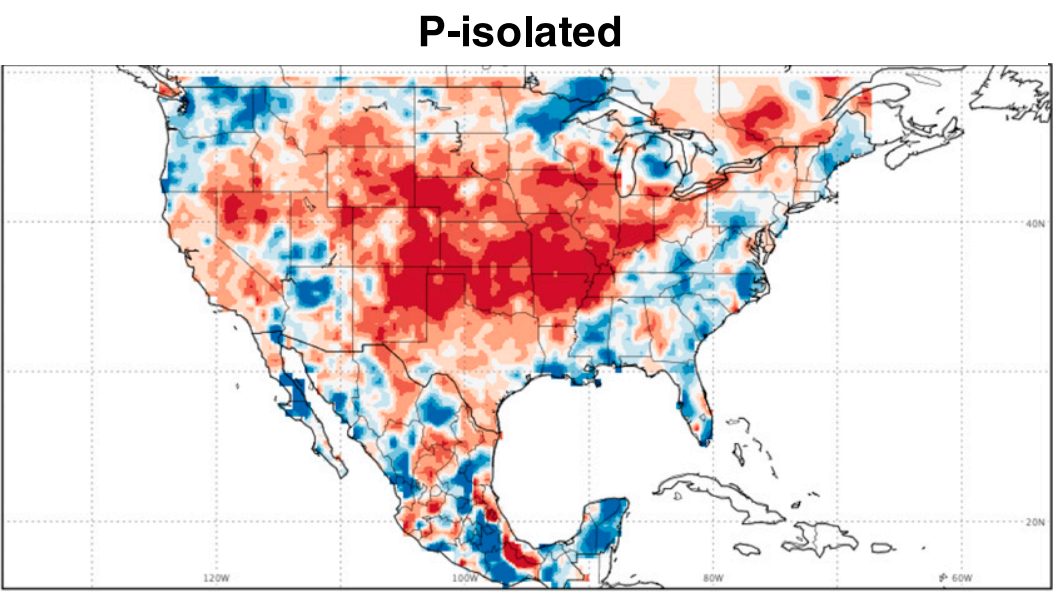

T-isolated

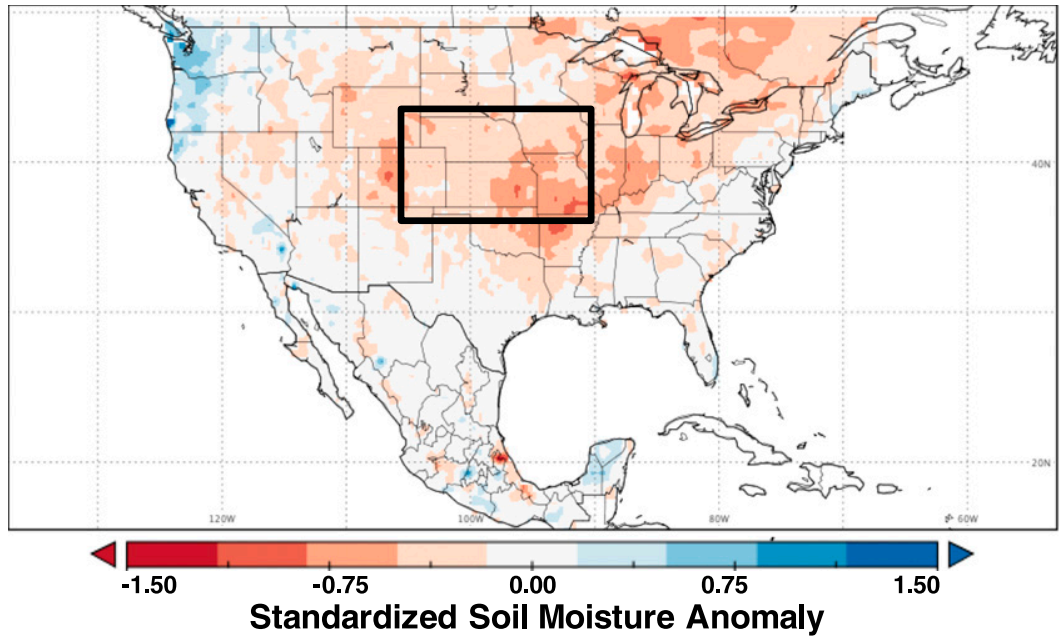

FIG. 6. Map of monthly August standardized anomalies (1981-2010 reference) for isolated (top) precipitation and (bottom) temperature impacts that can be compared against Fig. 1d, to illustrate the dominant influence of precipitation on soil moisture deficits. The seasonal (MJJA) anomalies are listed directly on the plot for VIC, relative to the $1.40 \sigma$ anomaly of the baseline 2012 simulation.

has statistically significant autocorrelation $(\alpha=0.05)$ beyond 18 months.

Given the strong seasonal cycle of Great Plains climatological precipitation with a single late spring peak, Fig. 9 shows soil moisture autocorrelations for two different start months-one immediately before the wet season (March initial month) and the other immediately after (October initial month). The results indicate that soil moisture memory is appreciably disrupted by forthcoming rainy season precipitation (Fig. 9, top), with autocorrelation becoming statistically insignificant $(\alpha=$ 0.05 ) after 8 months for all cases. Alternatively, soil moisture is more persistent in the aftermath of the rainy season (Fig. 9, bottom) exhibiting statistically significant autocorrelation $(\alpha=0.05)$ for 10 months for all models.
As such, soil moisture predictability based solely on its autocorrelation will be strongly seasonally dependent, having greater predictive skill from initialized states in late summer than from initialized states in late winter. The models ECHAM5 and VIC-GCM capture this key characteristic of the soil moisture autocorrelation, but have a slightly greater persistence than the observationally driven soil moisture ahead of the wet season (note that the observational run is within the model ensemble spread). The greatest difference in persistence between the two starting months occurs between months 3 and 6 , which are lag times especially relevant for seasonal forecasting.

Aside from the soil moisture memory, additional predictability will emerge if the meteorological drivers 

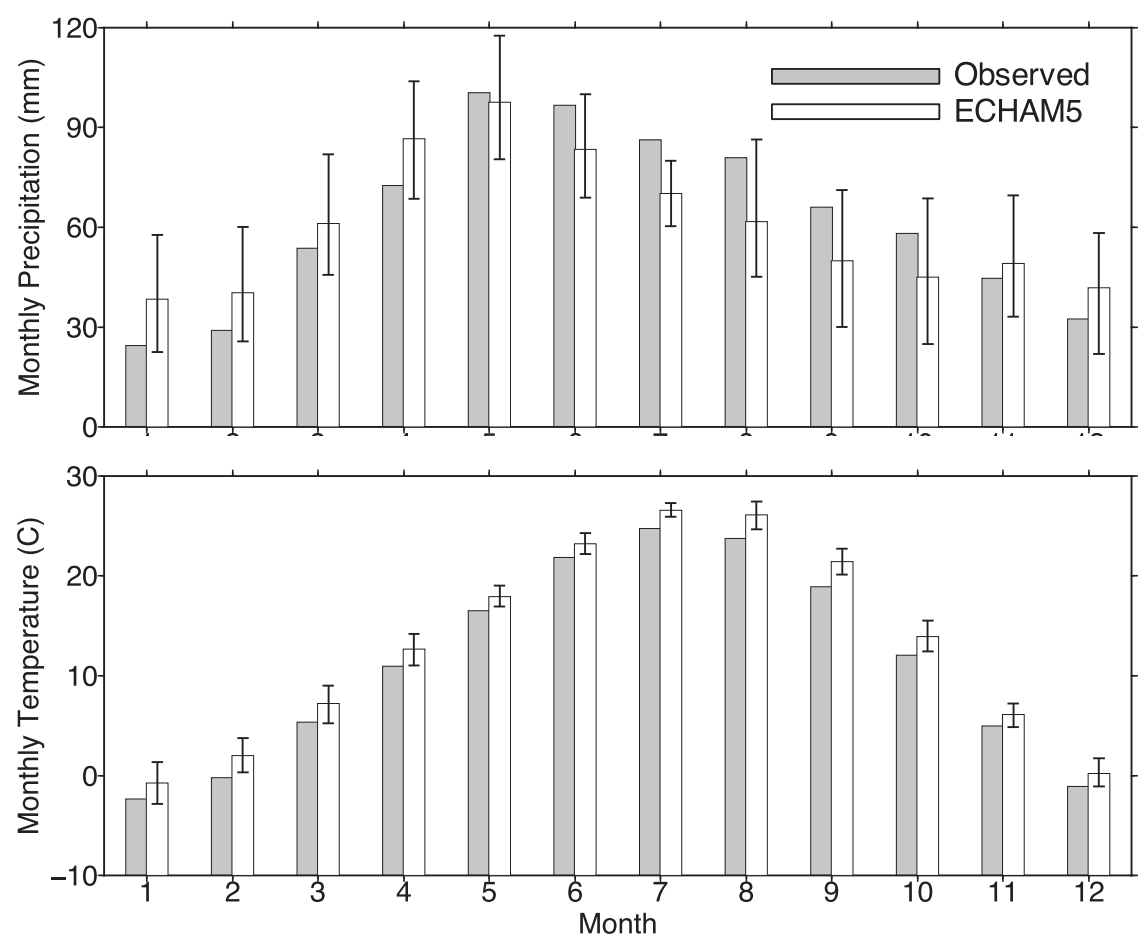

FIG. 7. Mean monthly meteorology (1979-2013) over the Great Plains domain for observations (Livneh et al. 2015) and 30-member ensemble mean ECHAM5 values (white bars), where error bars denote minimum and maximum member values.

of the land surface are themselves predictable. An important factor driving meteorological variability over the Great Plains is ENSO (e.g., Hoerling et al. 2014), and it is reasonable to expect that ENSO-related meteorological signals will be a key predictor for soil moisture variations. ECHAM5 has a realistic precipitation response to ENSO over the Great Plains, as confirmed by a comparison of seasonal precipitation regressed upon a Niño-3.4 SST index for the model and for observations from the Global Precipitation Climatology Centre (GPCC; Schneider et al. 2014). The comparisons (see Figs. S1 and S2 in the supplemental material) indicate a May-August wet signal during El Niño and confirm that ECHAM5 captures essential seasonal ENSO climate impacts over the Great Plains. Although our purpose here is not to assess the predictability

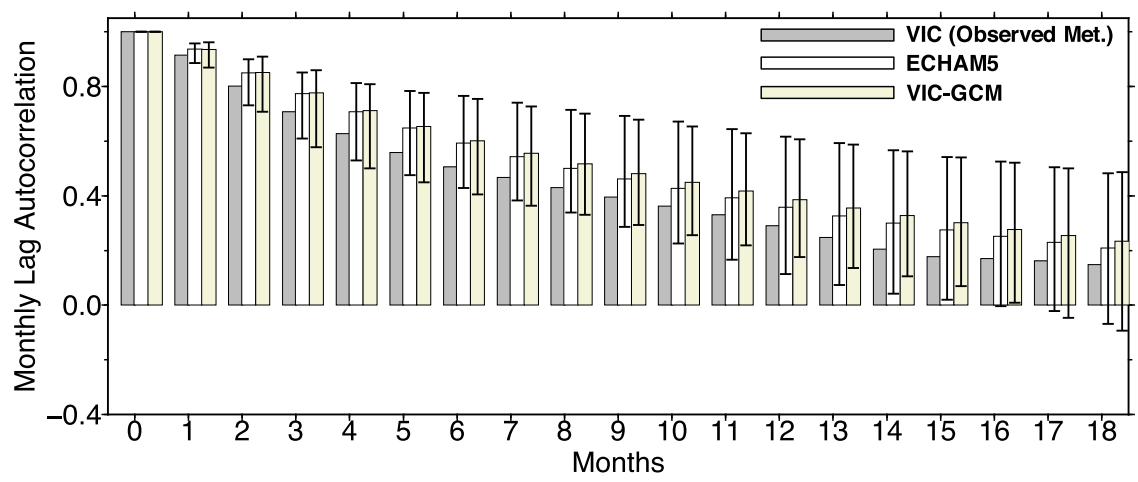

FIG. 8. Monthly lag autocorrelation of soil moisture comparing monthly anomalies of VIC driven by observed meteorology (1979-2013) with both the soil moisture from the 30-member ECHAM5 ensemble and the VIC driven by ECHAM5 meteorology (VIC-GCM) for the same period over the Great Plains domain; error bars denote minimum and maximum member values; all models have significant $(\alpha=0.05)$ autocorrelation beyond 18 months. 

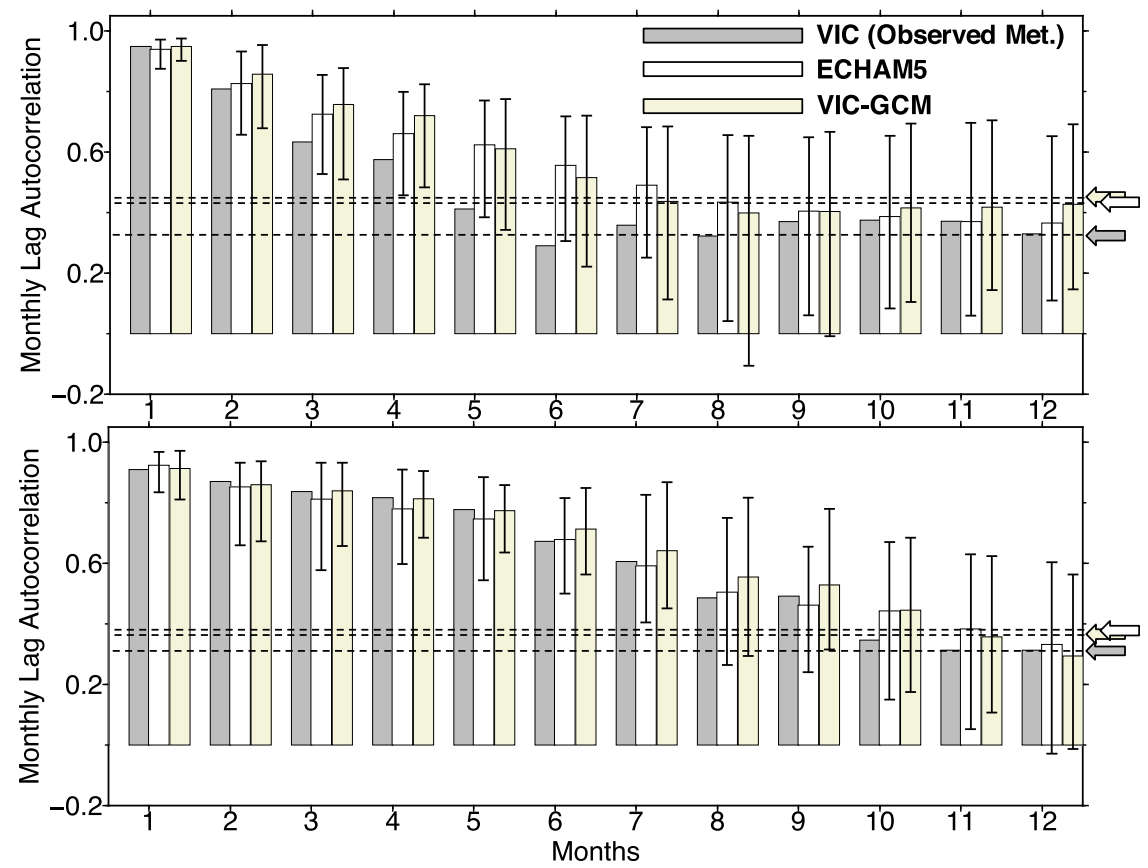

FIG. 9. As in Fig. 7, but for monthly soil moisture lag autocorrelation starting in (top) March and (bottom) October. Autocorrelation becomes statistically insignificant $(\alpha=0.05)$ for VIC-GCM in month 7 and ECHAM and VIC driven by observations in month 8 for the March start (significance threshold denoted by horizontal dashed lines and arrows colored by model), while all models preserve significant autocorrelation $(\alpha=0.05)$ through 10 months for the October start.

of ENSO itself, we merely note that the potential predictability may entail a useful discrimination of high and low soil moisture based on ENSO phase. This will demonstrated subsequently (see Fig. 13) where we stratify the dry soil moisture occurrences during summer according to ENSO phase, and show a nearly threefold increase in severe low soil moisture states when ENSO is in its cold (La Niña) phase compared to its warm (El Niño) phase.

Aside from these important considerations of drought predictability, it is important to address first the physics of the surface energy exchange that characterize drought situations. Here we diagnosis the near-surface energy exchange during May-August from the ECHAM5 and VIC model data, with a particular focus on the lowest soil moisture cases. Figures 10a and 10b show the scatter relations between soil moisture and precipitation and temperature, respectively. We comingle the values from VIC-GCM with the ECHAM5 land model results for 1050 years of data. The sample of $1 \%$ of the lowest MJJA precipitation is shown in red circles for ECHAM (red crosses for VIC-GCM). A general linear relationship between soil moisture and precipitation is apparent as highlighted previously from the observations in Fig. 3 $(R=0.62)$, which is greater for the ECHAM ensemble $(R=0.77)$. By contrast, a weaker linear relationship exists for soil moisture and temperature in the observed case 1979-2013 $(R=-0.41)$, whereas this relationship is notably stronger even than precipitation for the ECHAM ensemble $(R=0.82)$. Despite this stronger relationship, a qualitative examination of Fig. 10b shows positive temperature departures from the linear model during the most severe soil moisture deficits, suggesting that extreme heating can nevertheless result from dry soil conditions.

The physics of the soil moisture-temperature relationship is fundamentally tied to the surface turbulent energy exchange, as indicated in Fig. 10c. The Bowen ratio [see Eq. (1)] exhibits a strong nonlinear relationship with soil moisture over the Great Plainslatent heating vanishes rapidly (Bowen ratio increases abruptly) as soil moisture deficits exceed 1 standard deviation. This amplification of temperature extremes (i.e., the occurrence of hot summers) is thus often a symptom of the increased fraction of upward energy flux apportioned to sensible rather than latent heating during more severe soil moisture deficits. Both ECHAM5 and VIC-GCM portray this tendency toward enhanced summertime warming through excessive sensible heating and reduced latent heating (Fig. S3), with the largest anomalies occurring May-September, peaking in July. The precise extreme sensitivity that 

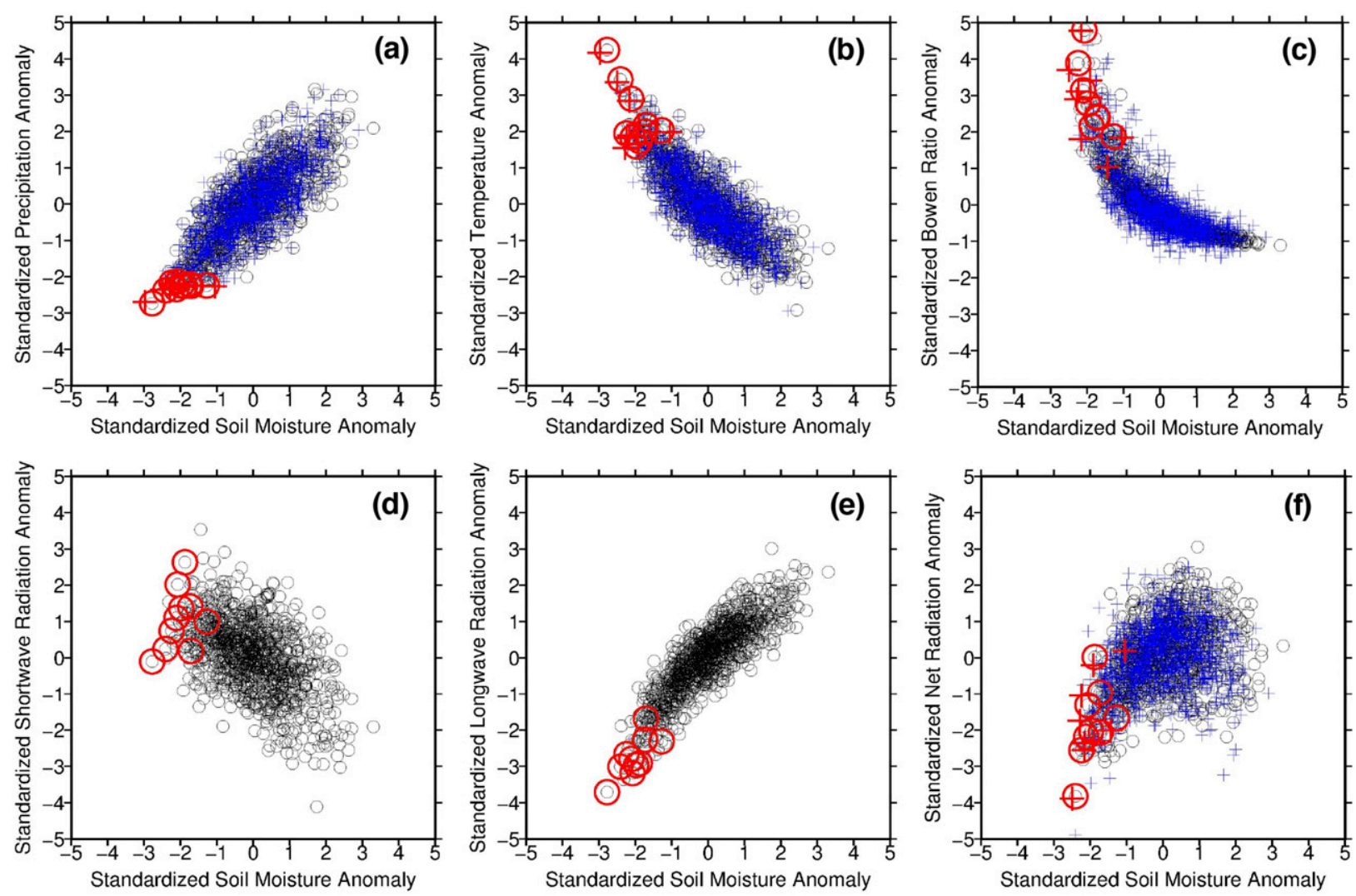

FIG. 10. Comparison of MJJA standardized anomalies for various states and fluxes on the ordinate axes between ECHAM5 (circles) and VIC (crosses) compared with soil moisture (abscissa), where the $1 \%$ lowest MJJA precipitation simulations are highlighted in red; all radiation terms are net fluxes and are only included for ECHAM5, as it treats radiation explicitly. The Bowen ratio has a single extreme point that falls above the ordinate at approximately $6.2 \sigma$.

occurs in any particular region will likely depend on whether a region has a soil-moisture-limited ET regime or an energy-limited ET regime, as was shown by Hirschi et al. (2011) in a study that contrasted soil moisture deficithot summer linkages over central versus eastern Europe. A key aspect of our findings that builds on existing understanding of the physics of drought is that, as per land model experiments, the direct effects of temperature on soil moisture deficits are secondary to overall effects of precipitation. Together with the energy balance calculations, extremes in surface temperatures from year-to-year are thus shown herein to be principally a response to rather than a driver of drought. This result does not address how the character of droughts, and their associated heat waves, will behave in a warmer world, a point we return to in section 4.

Additional features of the surface energy balance are that longwave radiation is strongly constrained by soil moisture, consistent with strong temperature response to precipitation conditions (Fig. 10e). Longwave radiation is thus a braking mechanism on the surface temperature response. By contrast, shortwave radiation anomalies exhibit a somewhat inverted relationship (Fig. 10d). Whereas there is increased shortwave radiation during low soil moisture states as would be physically consistent with an overall reduction in cloud cover accompanying reduced precipitation, there is a considerable range in the surface solar radiation among the sample of $1 \%$ driest states. ECHAM5 simulates solar radiation that is generally above normal during drought conditions; however, for some of the most severe droughts in the model, solar radiation can be near normal. This implies that while all those cases experience large precipitation deficits, overall summer cloud cover need not be appreciably diminished. In aggregate, net radiation is below average during soil moisture-driven drought, which, though perhaps counterintuitive, simply expresses the fact that high surface temperatures during droughts lead to stronger longwave cooling of the surface.

To examine the $1 \%$ lowest-MJJA-precipitation cases occurring in ECHAM5 more closely, standardized soil moisture anomaly time series are shown in Fig. 11, corresponding to the red highlighted cases from Fig. 10. For clarity the same traces are plotted in the inset as 


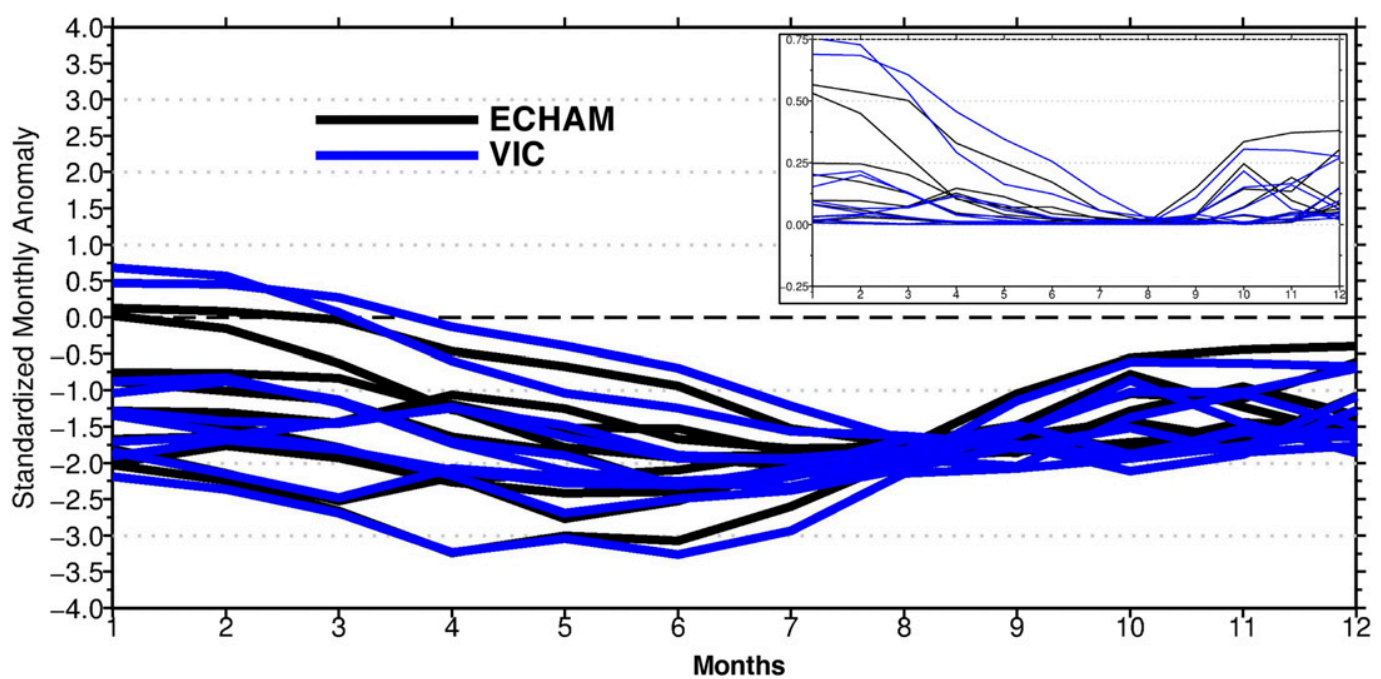

FIG. 11. Monthly standardized anomalies of ECHAM5 (black) and VIC-GCM; anomalies computed relative to 1981-2010 reference; plotted are those simulations with the 1\% lowest precipitation during the MJJA season for the 1050 ensemble years, representing 10 simulations from each model; the insert shows the same data only plotted as a percentile value since soil moisture becomes positively skewed by late summer.

ranked percentiles, illustrating that the apparent recovery in standardized soil moisture in August is an artifact resulting from the positive skew in soil moisture during the summer season. Importantly, the insert affirms that the soil moisture indeed reaches a minimum in August, consistent with the extreme summer rainfall deficit, and furthermore that the majority of driest summers have antecedent low soil moisture conditions in winter-early spring. This result can be understood by considering the effects of two physical processes: 1) low winter-early spring precipitation is itself commonly followed by low late spring/summer precipitation, perhaps via a low frequency ocean forcing (ENSO results presented below) and thus implies a potential for drought predictability; and 2) low winter-early spring soil moisture acts to inhibit subsequent summer precipitation and thus implies a positive feedback between soil moisture deficits and drought severity. To the extent either or both are operating, then the physics of drought shown in this figure speaks to predictability, which we quantify below. The selection of these MJJA low precipitation cases is motivated by the observed 2012 situation where MJJA precipitation was the lowest in the historical record. What is interesting here is that all (10 samples) had below-normal soil moisture preceding the summer (i.e., in April), implying that 2012 was unusual in that April 2012 soil moisture was estimated to have been near normal. Perhaps of greatest relevance to the physics of drought in Fig. 11 is the reduction in spread among soil moisture traces between April and Augustin effect, low-precipitation summers can be preceded by a great variety of antecedent conditions whereby the summer precipitation exerts a strong control on soil moisture as exemplified by the end-of-summer convergence.

An ancillary characterization of severe drought conditions is presented in Fig. 12 in which the 10 highestMJJA-temperature traces are shown. This result clearly shows that the hottest Great Plains summers have strong signals of antecedent low soil moisture. When compared to Fig. 11, the implication is that the very hot summers have predictability from the monitored state of winterearly spring soil moisture. This predictability of hot summers is considerably greater than the predictability of low precipitation summers. Of course, based on the result of Fig. 11, the processes of having selected the hottest Great Plains summers in the model is tantamount to having selected very low precipitation summers also, as temperature and precipitation are inherently inversely linked (Fig. 3). We count that exactly 3 out of the 10 traces in Figs. 11 and 12 are the same cases. Unlike the precipitation case, hot summers are more clearly preceded by dry springs with greater coherence in antecedent soil moisture. Strikingly, soil moisture by the end of summer shows less convergence for high temperature versus low precipitation cases (cf. Figs. 11 and 12), highlighting that temperature has less control on soil moisture than precipitation. This difference in drought signatures is confirmed in the percentile plots. To quantify the seasonal predictability of extreme drought more generally, we calculate the correlation between the lowest $1 \%$ soil moisture summers (MJJA) with their preceding spring [January-April (JFMA)] condition resulting in a correlation value of $R=0.89$. Despite this relatively high interseasonal correlation, we 


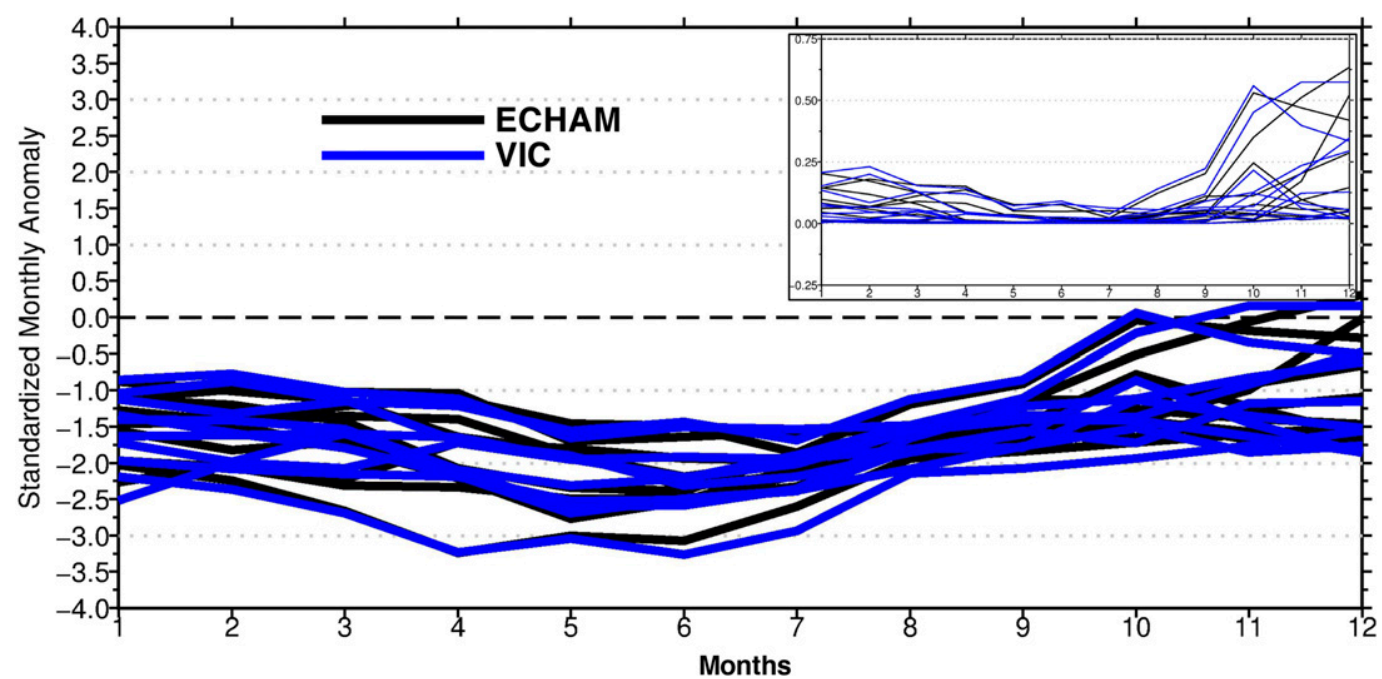

FIG. 12. As in Fig. 11, but for 1\% highest temperature.

note that only 2 (out of 10) of the spring (JFMA) extreme lowest $1 \%$ soil moisture cases are followed by extreme 1\% lowest soil moisture in the summer (MJJA), indicating that soil moisture in the most extreme dry regime (lowest $1 \%$ ) in spring is likely to emerge from this extreme state in the summer and does not offer appreciable predictability of sustained extreme severity.

\section{d. Analysis of predictability of drought development}

To further understand sources for the predictability of Great Plains drought implied in Figs. 11 and 12, we stratify the ECHAM5 data into El Niño and La Niña cases. Ten El Niño and ten La Niña years are identified during the simulation period of 1979-2013 based on a $0.5^{\circ} \mathrm{C}$ Niño-3.4 wintertime SST anomaly threshold for four consecutive months. We analyze the antecedent January-April land surface and meteorological conditions that precede the occurrences of the lower quartile May-August soil moisture conditions (i.e., summer droughts; Figs. 13a-c), and also the upper quartile MayAugust surface temperatures (i.e., hot summers; Figs. 13d-f). Recall that with a 30-member model ensemble, the total sample size is 1050 years, and the quartile subsample is for 262 drought years. If ENSO had no influence on Great Plains summer conditions, then 70 of those cases would be expected to be El Niños, $70 \mathrm{La}$ Niñas, and 122 ENSO neutral.

The vast majority of the summer drought events experienced antecedent dry soil moisture (Fig. 13a), low precipitation (Fig. 13b), and high temperatures (Fig. 13c), consistent with the extremes analysis shown in the prior section. The severity of warm season (MJJA) soil moisture deficits within the dry quartile range shows a clear relationship with the severity of preceding season moisture in Fig. 13a, explaining 27\% variance of subsequent summer soil moisture $(R=0.53)$, with less explained from antecedent season precipitation alone ( $\sim 16 \%$, Fig. $13 \mathrm{~b})$ and less still explained by temperature ( $\sim 8 \%$, Fig. $13 \mathrm{c})$.

The results in Fig. 13 further indicate that ENSO's phase significantly alters the probability of summer Great Plains drought. La Niña more than doubles the odds for climate conditions in winter that lead to severe drought in summer. By contrast, El Niño induces a more modest diminution of drought probability. Overall, the ECHAM5 simulations indicate a 3.5-fold increase in the odds of summertime severe drought during La Niña compared to El Niño.

At least two mechanisms may be operating by which ENSO affects Great Plains summer drought probabilities. One is via its influence on variability of antecedent conditions (soil moisture in particular) over the Great Plains, with subsequent persistence. Note that our previous results indicated that March initial soil states have a $\sim 0.5$ lag correlation with soil moisture states into summer (see Fig. 9), and as such ENSO-phase operates on summer drought probability by setting the likelihood for antecedent soil states. A second effect, which in some situations combines with the first, is ENSO's direct influence on summertime meteorological conditions over the Great Plains. Our analysis of the seasonal variability of the model's precipitation response to ENSO reveals that the composite La Niña drying signal that is prominent over the Great Plains in winter continues into summer whereas an El Niño summer wet signal wanes (not shown). This is in part owing to the typically longer lifetime of La Niña compared to El Niño, thus permitting the former to have a more 

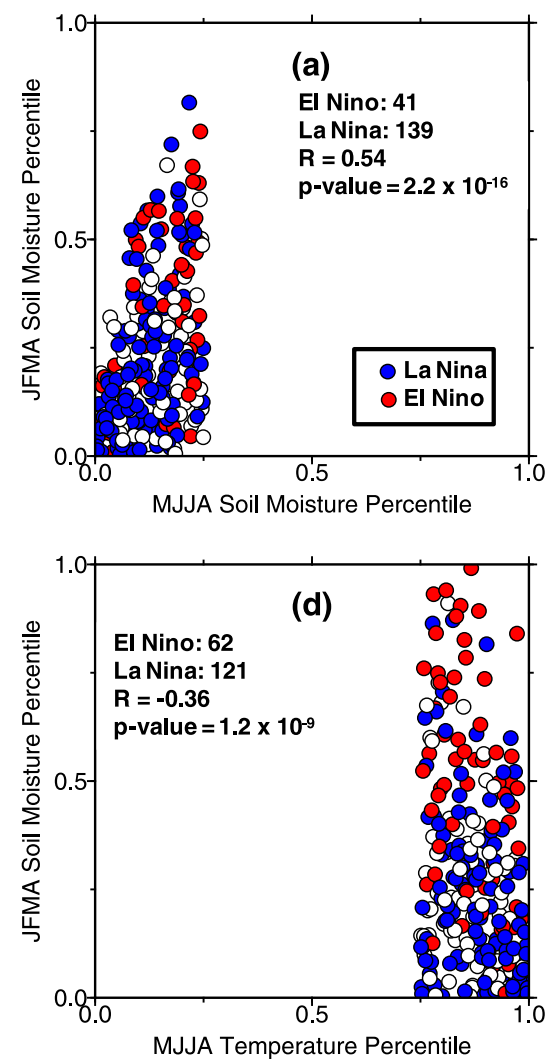
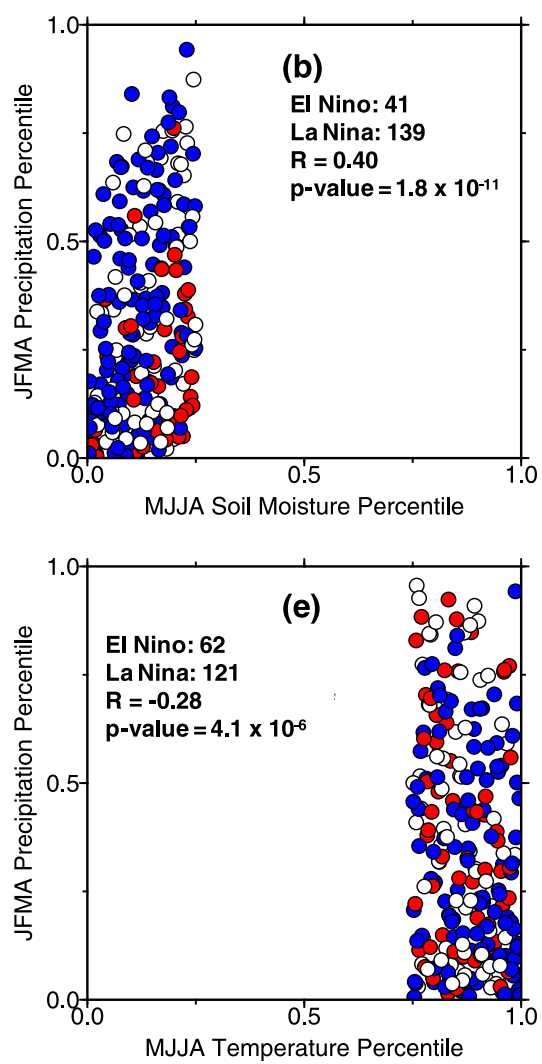
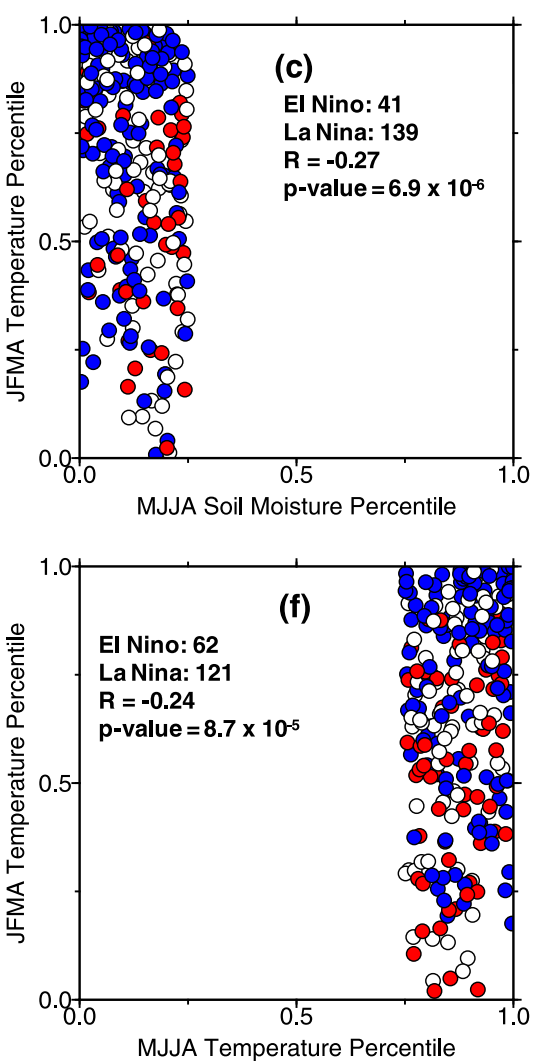

FIG. 13. Seasonal percentiles of summer (MJJA) (a)-(c) soil moisture and (d)-(f) temperature computed against preceding season (JFMA) soil moisture, temperature, and precipitation, isolating the lowest $25 \%$ soil moisture years in (a)-(c) and highest temperature years in (d)-(f) with data colored based on the Niño-3.4 index using an El Niño threshold of $>0.5^{\circ} \mathrm{C}$ and La Niña index of $<-0.5^{\circ} \mathrm{C}$ for four consecutive months, listing the count of points in each phase, the correlation among points, and the statistical significance ( $p$ value) of the slope of the points being different from zero. The El Niño years include 1983, 1987, 1988, 1992, 1995, 1998, 2003, 2005, 2007, and 2010; the La Niña years are 1984, 1985, 1989, 1996, 1999, 2000, 2001, 2008, 2011, and 2012.

persistent and enduring influence on cumulative soil moisture conditions by summer.

The severity of hot summers is less constrained by antecedent conditions. For instance, preceding season (JFMA) soil moisture explains only about $12 \%$ of variance of the summer temperatures within the upper quartile range (Fig. 13d), and preceding season precipitation $(7 \%)$ and temperature $(5 \%)$ are even less predictive. Figure 13 also illustrates that La Niña has an appreciable greater effect than El Niño in altering the odds for hot summers over the Great Plains. Overall, we enumerate instances in which low soil moisture springs (in the bottom $25 \%$ ) precede low soil moisture summers, finding this to occur in $62 \%$ of all cases, which suggests potential predictability of sustained drought conditions.

Although our results indicate that ENSO phase materially influences the odds of severe drought and hot summers over the Great Plains, we note that any factor that affects antecedent soil moisture acts to alter the subsequent summertime drought likelihood. We analyzed another long integration of the ECHAM5 model having no interannual variability of SSTs and found that JFMA soil moisture conditions in that set of experiments explained $16 \%$ variance of subsequent summer soil moisture (down from 27\% with ENSO) within the upper quartile $(R=0.40)$. The difference between these two sets of explained variances can be used to understand the importance of ENSO relative to other drivers of moisture variability, such as land-atmosphere moisture feedbacks. These antecedent dry states originated solely from internal atmospheric variations, which, although unpredictable at long leads, can generate detectable effects on land surface conditions that in turn enhance the predictability of summertime drought.

\section{Summary and discussion}

The physics of Great Plains drought were explored through an examination of the relationship between meteorological drivers-precipitation and temperatureand soil moisture deficits during the growing season (MJJA). LSM simulations reproduced key features in 
both the U.S. Drought Monitor and GRACE terrestrial water anomalies and ultimately showed that precipitation has driven the majority of Great Plains interannual soil moisture variability since 1950 . Energy balance considerations point toward an even larger net contribution of precipitation to soil moisture variability because growing season temperature variability is itself strongly driven by precipitation.

The 2012 Great Plains drought was placed in a historical context relative to years since 1950 with meteorological observations that were historically hot and dry for the MJJA period. While high temperatures during summer 2012 were record setting over the central Plains, higher than in any summer since 1950, those observations alone do not provide a strong argument that the drought itself was largely a consequence of the heat.

The reason is that precipitation was also a historical anomaly, being the driest since 1950 . We showed that these joint extreme meteorological conditions were consistent with a historical inverse $P-T$ relationship for this domain, the physics of which were shown to be symptomatic of precipitation mostly driving temperature. A detailed land surface model diagnosis was conducted using two LSMs to quantify the physics of the drought with respect to the impact of each meteorological forcing and the surface energy balance. The result indicated that on the order of $72 \%-80 \%$ of the central Great Plains soil moisture deficit during summer 2012 was attributable to precipitation forcing, which was likely greater when taking into account the inverse precipitation-temperature relationship.

The role of antecedent conditions for the 2012 drought was analyzed, and it was found that despite the depletion of near-surface soil moisture by high early spring temperatures, deep soil moisture was above normal owing to prior wet winter conditions. Hydrologic simulations confirmed that these somewhat favorable deep column soil conditions in advance of the 2012 growing season (MJJA) likely prevented the event from being more severe than it was. Further, the analysis indicated that earlier events such as the multiyear 1950s drought produced more severe soil moisture deficits, and highlighted the importance of antecedent conditions (i.e., carryover soil moisture storage).

The use of 1050 years of climate simulations representative of recent climate conditions enabled a broader examination of physics, confirming that growing season droughts arise mainly from rainfall deficits, with temperature mostly a response variable through the response of the surface energy exchange with the atmosphere. Conversely, antecedent wintertime meteorological and soil moisture conditions were shown to be of secondary importance to growing season soil moisture. Greater soil moisture persistence was exhibited following the wet season-in October-as opposed to starting before the wet season, March; this is an expression of the memory of the soil moisture to large moisture inputs, relevant for predictability.

The regional radiative balance revealed that drought conditions are generally associated with negative net radiation, driven by longwave radiative cooling. Additionally, a highly nonlinear response in Bowen ratio was observed, indicative of a quasi tipping point that occurs during drought when the great majority of solar energy goes into sensible heating of the land surface, consistent with the previous statement that terrestrial longwave emission dominates the surface energy balance during drought.

Highlighting the $1 \%$ lowest-precipitation MJJA periods strengthened the understanding of strong precipitation control on the physics of soil moisture evolution, in which a great diversity of initial moisture states entering MJJA (i.e., in April) closely converge by the end of the season. Conversely, the $1 \%$ hottest MJJA periods displayed a different character, with less convergence at summer's end, yet with greater similarity among events throughout the MJJA period and even in preceding months. This similarity among high-temperature droughts raised the question of potential predictability based on knowledge of antecedent moisture and meteorology.

The last phase of the analysis explored seasonal drought predictability, concluding that antecedent soil moisture had greatest the predictability potential, with approximately $27 \%$ of the variance of MJJA soil moisture explained by JFMA conditions. Temperature and precipitation were next most predictive, respectively. Drought conditions were more common during La Niña phases in this region such that removing the ENSO variability from the GCM simulations yielded a reduction in interseasonal soil moisture correlation by about 0.1 points.

\section{a. Discussion of Great Plains drought sensitivity to climate change}

How might land surface moisture respond to climate change? To explore the sensitivity for drought under different climate states, we superposed various synthetic climate signals upon the observed historical meteorology and reran VIC. Although the synthetic climate signal was applied over the entire Livneh et al. (2015) domain, only the Great Plains was analyzed here. The results shown in Fig. 14 look specifically at the 2012 event under imposed climate signals, both for reduced precipitation (by $10 \%$ and $20 \%$ ) and for higher temperatures (by $1^{\circ}, 2^{\circ}$, and $4^{\circ} \mathrm{C}$ ). The land surface responses indicate greater soil moisture deficits (compared to the actual 2012 historical simulation), 


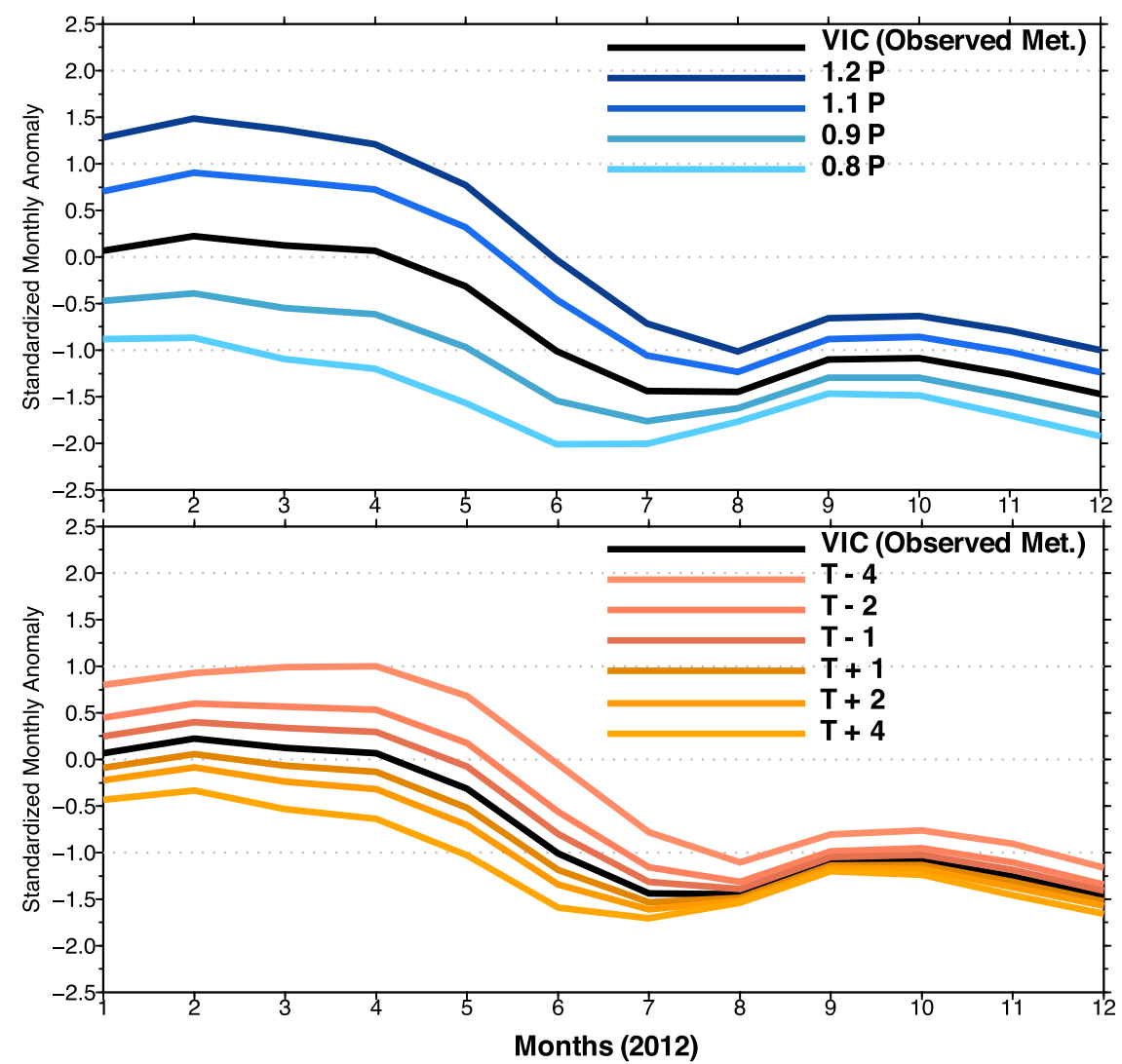

FIG. 14. Monthly standardized anomalies for 2012 (relative to 1981-2010) for VIC simulations using observed meteorology in black, with (top) synthetic precipitation scaling shown in blue shading and (bottom) synthetic temperature deltas shown in orange shading applied relative to observations for all months respectively.

with greater sensitivities to precipitation reductions than to temperature increases consistent with previous studies (e.g., Sheffield and Wood 2008). Temperature sensitivities are slightly asymmetric about the baseline conditions particularly for the $-4^{\circ} \mathrm{C}$ anomaly case. Additional ULM simulations exhibited similar asymmetry with overall slightly diminished sensitivities relative to VIC. Higher temperature scenarios suggest that under warmer climate conditions, a repeat of the 2012 drought would have resulted in soil moisture deficits enhanced by approximately 0.5 standardized departures or less. For reference, the Fifth Assessment Report (AR5) representative concentration pathway 8.5 (RCP8.5) ensemble average shows a statistically significant temperature warming of approximately $4^{\circ} \mathrm{C}$ for the Great Plains domain, near the magnitude of our most extreme warming scenario, while the range of the precipitation changes in Fig. 14 covers the ensemble spread of AR4 projections for the middle and late twenty-first century (IPCC 2013), and additionally span roughly the range of observed multidecadal precipitation variability since 1900 .
For all synthetic climate changes scenarios considered herein, the prominent seasonal cycle of Great Plains climatological precipitation (i.e., the MJJA wet season) was found to partially "reset" seasonal soil moisture deficits by the end of each year. Nonetheless, an overall annual drying signal of the land surface resulted, indicating that moisture deficits will likely be exacerbated by warming temperatures, consistent with previous studies based on the PDSI and SPEI (Cook et al. 2014) as well as GCM soil moisture (Cook et al. 2015). Other studies focusing on the relationship between simulated precipitation and evaporation (Seager et al. 2007, 2013, Dai 2013; Fu and Feng 2014; Scheff and Frierson 2015) derived from Coupled Model Intercomparison Project (CMIP) models also project enhanced likelihood for future drought. Cook et al. (2014) and Zhao and Dai (2015) both decompose drought into precipitation and evaporative components; however, the influence of temperature is implicit in evaporation changes, rather than explicit as in the current study. Williams et al. (2015) decomposed drivers of the contemporary 
California drought (2012-14) using PDSI finding precipitation as the dominant driver but reporting an approximately $8 \%-27 \%$ contribution from high temperatures, a number that is comparable to values reported here for the 2012 Great Plains droughts. Williams et al. (2015) and the present study generally stand alone among those aforementioned in terms of decomposing drought into its precipitation and temperature drivers, as others generally leave evaporative demand for evaporation, PET (comprising temperature, humidity, and radiative energy), as a single composite quantity.

\section{b. Conclusions}

The major theme of this manuscript was to clarify the physics between drought (via soil moisture deficits) and more readily observable meteorological phenomena: precipitation and temperature. The results offer insights into these relationships, indicating that precipitation is the dominant driver of soil moisture deficits in the Great Plains. The meteorological conditions favorable for summertime Great Plains drought are made more likely by the La Niña phase of ENSO, although ENSO is not a necessary condition.

How can the observed 2012 Great Plains drought be understood in the context of the general characteristics of severe summertime drought over the region identified in the current paper? One factor operating in 2012 was a La Niña event, which would have elevated severe drought odds. Early spring was also hot. However, LSM simulations indicated that antecedent soil moisture was not low in 2012, and thus a major factor for drought development was not in place by late spring 2012. In this sense, the occurrence of severe drought over the Great Plains was somewhat atypical in that initial soil conditions were not an appreciable factor. The key element was the extreme (record setting) deficit in summertime rains. The La Niña event was prolonged and persisted through summer 2012, and thus was likely a factor contributing to the low rainfall, as found in Hoerling et al. (2012). In this latter sense, the 2012 drought shared a common attribute with those found in the canonical situation.

The regional LSM approach applied here was designed to isolate the impact of distinct drought drivers over a relatively small domain, the Great Plains. This is in contrast to global CMIP-based studies in which the evolution of numerous independent variables makes direct interpretation of local drought drivers less straightforward. The Great Plains-focused scope of this study has enabled us to quantitatively decompose the influences of precipitation and temperature individually on drought. Regarding explicit assessments of temperature and precipitation change impacts on land surface moisture balances, such a study has largely been lacking in the literature [the work of Williams et al. (2015) notwithstanding], but one which is needed because there exists greater consensus among models regarding projected temperature changes as compared to precipitation changes. As such, isolating the effect of temperature alone on land surface conditions has potentially high predictive value concerning future drought regimes. Based on our results we speculate that temperature warming for the likely ranges of $2^{\circ}-4^{\circ} \mathrm{C}$ anticipated by the mid-twenty-first century will enhance land surface drying, while intrinsic rainfall variability will remain important and likely be the leading factor in land surface moisture variability for coming decades.

Although seasonal predictability of summer drought over the Great Plains was found to be sensitive to antecedent land surface conditions, the majority of the ensuing summertime soil moisture variance remains unexplained and would require knowledge of summertime rainfall variations in particular. Knowledge of ENSO phase may provide some further information on drought likelihood, although a more detailed analysis of the joint probability with antecedent conditions is required. Coordinated use of large-scale meteorological and soil moisture observations may enable follow-up analyses to further quantify the physical relationships studied here. Future efforts should be directed at transferring these methods to explore drought likelihood under future climate to other regions of interest, particularly those near the threshold of more frequent drought, such as the U.S. Southwest and California. Last, more detailed analysis into the role of projected changes cold-season processes (i.e., snowpack) and groundwater-surface water interactions on drought severity is recommended as many global regions rely on these sources for water supply.

Acknowledgments. The authors acknowledge the support from the NOAA's Climate Program Office (CPO) Modeling, Analysis, Predictions, and Projections Program (MAPP), NASA's MAP program, and the U.S. Global Change Research Program (USGCRP). We further acknowledge the assistance of Jon Eischeid for his assistance in compiling simulated and observed ENSO data. This work utilized the Janus supercomputer, which is supported by the National Science Foundation (Award CNS0821794) and the University of Colorado Boulder. The Janus supercomputer is a joint effort of the University of Colorado Boulder, the University of Colorado Denver and the National Center for Atmospheric Research. 


\section{APPENDIX}

\section{Description of Models}

\section{a. The Variable Infiltration Capacity model}

As described by Shukla et al. (2014) and Gao et al. (2010), the VIC model (Liang et al. 1994) has been widely used at a global scale and has been demonstrated to accurately capture the hydrology of different regimes (Nijssen et al. 1997, 2001; Maurer et al. 2002), including drought (e.g., Sheffield and Wood 2008; Sheffield et al. 2012). Distinguishing characteristics of the VIC model include subgrid variability in land surface vegetation classes (i.e., a mosaic of land cover); subgrid variability in the soil moisture storage capacity (statistically represented); nonlinear drainage from the lower soil moisture zone (base flow); and the inclusion of elevation bands in topographically complex regions that allows for orographic precipitation gradients and temperature lapse rates to be applied. Evapotranspiration is computed from a dynamically computed Penman-Monteith PET from which components of soil, canopy evaporation, and transpiration are estimated based on resistance terms that are a function of soil and plant stress. A full energy and water balance snow model (Andreadis et al. 2009) that simulates both canopy and subcanopy snowpack evolution is used.

In this study, the VIC model was built at a $0.5^{\circ}$ $(\sim 50 \mathrm{~km})$ spatial resolution. Soil parameters were derived from Livneh et al. (2013) for the continental U.S. (CONUS) domain and were upscaled from $0.0625^{\circ}$ to $0.5^{\circ}$ using areal averages. However, soil depths for the three soil layers were held constant within the Great Plains domain, so as not to introduce artificial discontinuities in soil response. The University of Maryland land cover classification system is used to assign different vegetation types (and bare soil) to each grid cell, which were upscaled directly from $0.0625^{\circ}$ to $0.5^{\circ}$, since VIC allows for a mosaic of land cover.

\section{b. The ECHAM5 model}

The ECHAM5 model takes part of its name "EC" from the European Centre for Medium-Range Weather Forecasts (ECMWF) model (Roeckner et al. 1989) and "HAM" from Hamburg, Germany. The details of ECHAM5 are summarized by Roeckner et al. (2003). However, briefly it is a general circulation model focusing on the coupling between diabatic processes and large-scale circulations, both of which are ultimately driven by radiative forcing (i.e., factors altering the balance of incoming and outgoing energy in the Earth-atmosphere system). The model consists of a dry spectral-transform dynamical core, a transport model for scalar quantities other than temperature and surface pressure, a suite of physical parameterizations for the representation of diabatic processes, and boundary datasets for externalized parameters, such as trace gas and aerosol distributions, tabulations of gas absorption optical properties, temporal variations in spectral solar irradiance, land surface properties, etc. (Stevens et al. 2013).

In this study, the ECHAM5 model was implemented at a $0.75^{\circ}$ resolution with a single vertical layer, with variable storage capacity. The soil scheme within the model is therefore a single bucket in which the storage capacity of the soil is represented by a set of values with a probability density function (Roeckner et al. 2003). A "storage capacity distribution curve" is defined that represents the fraction $f_{\mathrm{ws}}$ of the grid cell in which the storage capacity is less or equal to current soil water storage $h_{\mathrm{ws}}$ :

$$
f_{\mathrm{ws}}=1-\left(1-h_{\mathrm{ws}} / h_{\mathrm{cws}}\right)^{b},
$$

where $h_{\text {cws }}$ is the maximum soil water storage and $b$ is a shape parameter that defines the subgrid-scale characteristics of the basin or grid cell.

\section{c. The Unified Land Model}

The ULM (Livneh et al. 2011) represents the merger of two commonly used models, taking the vegetation, snow model, and evapotranspiration schemes from the Noah LSM [used in most of the National Oceanic and Atmospheric Administration (NOAA) atmospheric models] and merging them with the soil moisture accounting scheme from the Sacramento soil moisture accounting model (Sac; Burnash et al. 1973), the primary hydrologic prediction model within the National Weather Service. In summary, ULM uses a bulk surface layer with a single (dominant) vegetation class and snowpack [updated by Livneh et al. (2010)], overlying the conceptual, bucket-style soil representation of Sac. The vegetation canopy cover varies spatially and temporally by a monthly specified greenness fraction $G_{\mathrm{vf}}$ (Gutman and Ignatov 1998), derived from the photosynthetically active portion of leaf area index (LAI) based on a monthly climatology of AVHRR satellite data. Model calibrations and regionalization were carried out by Livneh and Lettenmaier (2012) and Livneh and Lettenmaier (2013) on over 200 river basins in the CONUS domain. In this analysis ULM was run at the same spatial resolution as VIC $\left(0.5^{\circ}\right)$ using of two soil zones (upper and lower) and five water storage "buckets." 
Similar to Livneh et al. (2014), the Mountain Microclimate Simulation Model (MT-CLIM) version 4.3 (Thornton et al. 2000) was applied to estimate the full suite of ULM required forcings, derived from daily precipitation and minimum and maximum temperatures. To provide the models with subdaily ( 3 hourly) temperature and derived forcings, a spline was applied to daily minimum and maximum temperatures to estimate the diurnal cycle and precipitation partitioned uniformly. An analysis performed by Maurer et al. (2002) into the impact of the same temperature spline and uniform precipitation assumptions found that neither had a substantial impact on the longterm average diurnal cycle of the energy budget or the partitioning of precipitation into runoff and evapotranspiration. These were output from the VIC preprocessor that estimates downwelling radiation and vapor pressure from the aforementioned quantities, to ensure consistency across models. Livneh et al. (2014) conducted comparisons of derived humidity and downwelling shortwave and longwave radiation with energy budget towers at the Niwot Ridge Long Term Ecological Research site (Boulder Creek; http://culter.colorado.edu/NWT/) and Senator Beck basin (Uncompaghre River; www.snowstudies.org). They computed small net biases but larger mean absolute errors, suggesting that derived quantities represent long-term (i.e., greater than daily) forcing well, but would not capture larger subdaily anomalies.

\section{REFERENCES}

Andreadis, K. M., P. Storck, and D. P. Lettenmaier, 2009: Modeling snow accumulation and ablation processes in forested environments. Water Resour. Res., 45, W05429, doi:10.1029/ 2008WR007042.

Basara, J. B., J. N. Maybourn, C. M. Peirano, J. E. Tate, P. J. Brown, J. D. Hoey, and B. R. Smith, 2013: Drought and associated impacts in the Great Plains of the United States-A review. Int. J. Geosci., 4, 72-81, doi:10.4236/ ijg.2013.46A2009.

Burnash, R. J. C., R. L. Ferral, and R. A. McGuire, 1973: A generalized streamflow simulation system-Conceptual modeling for digital computers. Joint Federal and State River Forecast Center Tech. Rep., U.S. National Weather Service and California Department of Water Resources (Sacramento), 204 pp.

Chang, F. C., and J. M. Wallace, 1987: Meteorological conditions during heat waves and droughts in the United States Great Plains. Mon. Wea. Rev., 115, 1253-1269, doi:10.1175/ 1520-0493(1987)115<1253:MCDHWA $>2.0$. CO;2.

Cook, B. I., J. E. Smerdon, R. Seager, and S. Coats, 2014: Global warming and 21st century drying. Climate Dyn., 43, 2607-2627, doi:10.1007/s00382-014-2075-y.

— , T. R. Ault, and J. E. Smerdon, 2015: Unprecedented 21st century drought risk in the American Southwest and Central Plains. Sci. Adv., 1, e1400082, doi:10.1126/sciadv.1400082.

Cook, E. R., R. Seager, M. A. Cane, and D. W. Stahle, 2007: North American drought: Reconstructions, causes, and consequences. Earth Sci. Rev., 81, 93-134, doi:10.1016/ j.earscirev.2006.12.002.

Dai, A., 2013: Increasing drought under global warming in observations and models. Nat. Climate Change, 3, 52-58, doi:10.1038/nclimate1633.

Dhuyvetter, K. C., C. R. Thompson, C. A. Norwood, and A. D. Halvorson, 1996: Economics of dryland cropping systems in the Great Plains: A review. J. Prod. Agric., 9, 216-222, doi:10.2134/jpa1996.0216.

Dole, R., and Coauthors, 2014: The making of an extreme event: Putting the pieces together. Bull. Amer. Meteor. Soc., 95, 427440, doi:10.1175/BAMS-D-12-00069.1.

Durre, I., J. M. Wallace, and D. P. Lettenmaier, 2000: Dependence of extreme daily maximum temperatures on antecedent soil moisture in the contiguous United States during summer. J. Climate, 13, 2641-2651, doi:10.1175/ 1520-0442(2000)013<2641:DOEDMT>2.0.CO;2.

Ek, M. B., K. E. Mitchell, Y. Lin, E. Rogers, P. Grunmann, V. Koren, G. Gayno, and J. D. Tarpley, 2003: Implementation of Noah land surface model advances in the National Centers for Environmental Prediction operational mesoscale Eta model. J. Geophys. Res., 108, 8851, doi:10.1029/2002JD003296.

Fu, Q., and S. Feng, 2014: Responses of terrestrial aridity to global warming. J. Geophys. Res., 119, 7863-7875, doi:10.1002/ 2014JD021608.

Gao, H., and Coauthors, 2010: Water budget record from Variable Infiltration Capacity (VIC) Model. Algorithm Theoretical Basis Document for Terrestrial Water Cycle Data Records, $1-41$.

Georgakakos, K. P., D. H. Bae, and D. R. Cayan, 1995: Hydroclimatology of continental watersheds: 1 . Temporal analyses. Water Resour. Res., 31, 655-675, doi:10.1029/94WR02375.

Gutman, G., and A. Ignatov, 1998: The derivation of the green vegetation fraction from NOAA/AVHRR data for use in numerical weather prediction models. Int. J. Remote Sens., 19 , 1533-1543, doi:10.1080/014311698215333.

Harris, I., P. D. Jones, T. J. Osborn, and D. H. Lister, 2014: Updated high-resolution grids of monthly climatic observations-The CRU TS3.10 dataset. Int. J. Climatol., 34, 623-642, doi:10.1002/ joc.3711.

Hirschi, M., and Coauthors, 2011: Observational evidence for soilmoisture impact on hot extremes in southeastern Europe. Nat. Geosci., 4, 17-21, doi:10.1038/ngeo1032.

Hoerling, M. P., J. K. Eischeid, X. W. Quan, H. F. Diaz, R. S. Webb, R. M. Dole, and D. R. Easterling, 2012: Is a transition to semipermanent drought conditions imminent in the U.S. Great Plains? J. Climate, 25, 8380-8386, doi:10.1175/JCLI-D-12-00449.1. , and Coauthors, 2013: Anatomy of an extreme event. J. Climate, 26, 2811-2832, doi:10.1175/JCLI-D-12-00270.1.

Hoerling, M., J. Eischeid, A. Kumar, R. Leung, A. Mariotti, K. Mo, S. Schubert, and R. Seager, 2014: Causes and predictability of the 2012 Great Plains drought. Bull. Amer. Meteor. Soc., 95, 269-282, doi:10.1175/BAMS-D-13-00055.1.

Huang, J., H. M. van den Dool, and K. P. Georgarakos, 1996: Analysis of model-calculated soil moisture over the United States (1931-1993) and applications to long-range temperature forecasts. J. Climate, 9, 1350-1362, doi:10.1175/ 1520-0442(1996)009<1350:AOMCSM>2.0.CO;2.

IPCC, 2013: Climate Change 2013: The Physical Science Basis. T. F. Stocker et al., Eds., Cambridge University Press, 1535 pp.

Liang, X., D. P. Lettenmaier, E. F. Wood, and S. J. Burges, 1994: A simple hydrologically based model of land surface water and 
energy fluxes for general circulation models. J. Geophys. Res., 99, 14 415-14 428, doi:10.1029/94JD00483.

Livneh, B., and D. P. Lettenmaier, 2012: Multi-criteria parameter estimation for the Unified Land Model. Hydrol. Earth Syst. Sci., 16, 3029-3048, doi:10.5194/hess-16-3029-2012.

—_, and — 2013: Regional parameter estimation for the Unified Land Model. Water Resour. Res., 49, 100-114, doi:10.1029/ 2012WR012220.

— , Y. Xia, K. E. Mitchell, M. B. Ek, and D. P. Lettenmaier, 2010: Noah LSM snow model diagnostics and enhancements. J. Hydrometeor., 11, 721-738, doi:10.1175/2009JHM1174.1.

_ P. J. Restrepo, and D. P. Lettenmaier, 2011: Development of a unified land model for prediction of surface hydrology and land-atmosphere interactions. J. Hydrometeor., 12, 12991320, doi:10.1175/2011JHM1361.1.

—_, E. A. Rosenberg, C. Lin, B. Nijssen, V. Mishra, K. M. Andreadis, E. P. Maurer, and D. P. Lettenmaier, 2013: A long-term hydrologically based dataset of land surface fluxes and states for the conterminous United States: Update and extensions. J. Climate, 26, 9384-9392, doi:10.1175/ JCLI-D-12-00508.1.

_ J. S. Deems, D. Schneider, J. J. Barsugli, and N. P. Molotch, 2014: Filling in the gaps: Inferring spatially distributed precipitation from gauge observations over complex terrain. Water Resour. Res., 50, 8589-8610, doi:10.1002/ 2014WR015442.

—, T. J. Bohn, D. W. Pierce, F. Munoz-Arriola, B. Nijssen, R. Vose, D. R. Cayan, and L. Brekke, 2015: A spatially comprehensive, hydrometeorological data set for Mexico, the US, and southern Canada 1950-2013. Sci. Data, 2, 150042, doi:10.1038/sdata.2015.42.

Luo, L., and E. F. Wood, 2007: Monitoring and predicting the 2007 US drought. Geophys. Res. Lett., 34, L22702, doi:10.1029/ 2007GL031673.

Madden, R., and J. Williams, 1978: The correlation between temperature and precipitation in the United States and Europe. Mon. Wea. Rev., 106, 142-147, doi:10.1175/ 1520-0493(1978)106<0142:TCBTAP $>2.0 . C O ; 2$.

Maurer, E. P., A. W. Wood, J. C. Adam, D. P. Lettenmaier, and B. Nijssen, 2002: A long-term hydrologically based dataset of land surface fluxes and states for the conterminous United States. J. Climate, 15, 3237-3251, doi:10.1175/ 1520-0442(2002)015<3237:ALTHBD>2.0.CO;2.

Mesinger, F., and Coauthors, 2004: NCEP North American regional reanalysis. 15th Symp. on Global Change and Climate Variations, Seattle, WA, Amer. Meteor. Soc., P1.1. [Available online at https://ams.confex.com/ams/84Annual/techprogram/ paper_72502.htm.]

Namias, J., 1960: Factors in the initiation, perpetuation, and termination of drought. Publication 51 of the IASH Commission of Surface Waters, International Association of Hydrological Sciences, 81-94. [Available online at http://hydrologie.org/ redbooks/a051/051010.pdf.]

Nijssen, B., D. P. Lettenmaier, X. Liang, S. W. Wetzel, and E. F. Wood, 1997: Streamflow simulation for continental-scale river basins. Water Resour. Res., 33, 711-724, doi:10.1029/ 96WR03517.

_ R. Rchnur, and D. P. Lettenmaier, 2001: Global retrospective estimation of soil moisture using the variable infiltration capacity land surface model, 1980-93. J. Climate, 14, 1790-1808, doi:10.1175/1520-0442(2001)014<1790:GREOSM>2.0.CO;2.

Palmer, W. C., 1965: Meteorological Drought. U.S. Department of Commerce, Weather Bureau, 58 pp.
Quan, X.-W., M. P. Hoerling, B. Lyon, A. Kumar, M. A. Bell, M. K. Tippett, and H. Wang, 2012: Prospects for dynamical prediction of meteorological drought. J. Appl. Meteor. Climatol., 51, 1238-1252, doi:10.1175/JAMC-D-11-0194.1.

Roeckner, E., L. Dümenil, E. Kirk, F. Lunkeit, M. Ponater, B. Rockel, and U. Schlese, 1989: The Hamburg version of the ECMWF model (ECHAM): Research activities in atmospheric and oceanic modelling. WMO-TD-332, 7-1-7.4.

—, G. Bäuml, L. Bonaventura, R. Brokopf, M. Esch, M. Giorgetta, and A. Tompkins, 2003: The atmospheric general circulation model ECHAM 5. Part I: Model description. MPI Rep. 349, 127 pp.

Scheff, J., and D. M. Frierson, 2015: Terrestrial aridity and its response to greenhouse warming across CMIP5 climate models. J. Climate, 28, 5583-5600, doi:10.1175/JCLI-D-14-00480.1.

Schneider, U., A. Becker, P. Finger, A. Meyer-Christoffer, M. Ziese, and B. Rudolf, 2014: GPCC's new land surface precipitation climatology based on quality-controlled in situ data and its role in quantifying the global water cycle. Theor. Appl. Climatol., 115, 15-40, doi:10.1007/s00704-013-0860-x.

Schubert, S. D., M. J. Suarez, P. J. Pegion, R. D. Koster, and J. T. Bacmeister, 2004: Causes of long-term drought in the U.S. Great Plains. J. Climate, 17, 485-503, doi:10.1175/ 1520-0442(2004)017<0485:COLDIT>2.0.CO;2.

,,,---- , and,- 2008 : Potential predictability of long-term drought and pluvial conditions in the U.S. Great Plains. J. Climate, 21, 802-816, doi:10.1175/2007JCLI1741.1.

Seager, R., and M. P. Hoerling, 2014: Atmosphere and ocean origins of North American droughts. J. Climate, 27, 4581-4606, doi:10.1175/JCLI-D-13-00329.1.

C, and Coauthors, 2007: Model projections of an imminent transition to a more arid climate in southwestern North America. Science, 316, 1181-1184, doi:10.1126/science.1139601.

—, M. Ting, C. Li, N. Naik, B. Cook, J. Nakamura, and H. Liu, 2013: Projections of declining surface-water availability for the southwestern United States. Nat. Climate Change, 3, 482-486, doi:10.1038/nclimate1787.

- L. Goddard, J. Nakamura, N. Henderson, and D. E. Lee, 2014: Dynamical causes of the 2010/11 Texas-northern Mexico drought. J. Hydrometeor., 15, 39-68, doi:10.1175/ JHM-D-13-024.1.

Seneviratne, S. I., T. Corti, E. L. Davin, M. Hirschi, E. B. Jaeger, I. Lehner, B. Orlowsky, and A. J. Teuling, 2010: Investigating soil moisture-climate interactions in a changing climate: A review. Earth Sci. Rev., 99, 125-161, doi:10.1016/ j.earscirev.2010.02.004.

Sheffield, J., and E. F. Wood, 2008: Global trends and variability in soil moisture and drought characteristics, 1950-2000, from observation-driven simulations of the terrestrial hydrologic cycle. J. Climate, 21, 432-458, doi:10.1175/2007JCLI1822.1.

, B. Livneh, and E. F. Wood, 2012: Representation of terrestrial hydrology and large-scale drought of the continental US from the North American Regional Reanalysis. J. Hydrometeor., 13, 856-876, doi:10.1175/JHM-D-11-065.1.

Shukla, S., A. McNally, G. Husak, and C. Funk, 2014: A seasonal agricultural drought forecast system for food-insecure regions of East Africa. Hydrol. Earth Syst. Sci., 18, 3907-3921, doi:10.5194/hess-18-3907-2014.

Stevens, B., and Coauthors, 2013: Atmospheric component of the MPI-M Earth System Model: ECHAM6. J. Adv. Model. Earth Syst., 5, 146-172, doi:10.1002/jame.20015.

Thornton, P. E., H. Hasenauer, and M. A. White, 2000: Simultaneous estimation of daily solar radiation and humidity from 
observed temperature and precipitation: An application over complex terrain in Austria. Agric. For. Meteor., 104, 255-271, doi:10.1016/S0168-1923(00)00170-2.

Trenberth, K. E., A. Dai, G. van der Schrier, P. D. Jones, J. Barichivich, K. R. Briffa, and J. Sheffield, 2014: Global warming and changes in drought. Nat. Climate Change, 4, 1722, doi:10.1038/nclimate2067.

Vicente-Serrano, S. M., G. Van der Schrier, S. Beguería, C. AzorinMolina, and J. I. Lopez-Moreno, 2015: Contribution of precipitation and reference evapotranspiration to drought indices under different climates. J. Hydrol., 526, 42-54, doi:10.1016/ j.jhydrol.2014.11.025.

Wang, H., S. D. Schubert, M. J. Suarez, J. Chen, M. Hoerling, A. Kumar, and P. Pegion, 2009: Attribution of the seasonality and regionality in climate trends over the United States during 1950 2000. J. Climate, 22, 2571-2590, doi:10.1175/2008JCLI2359.1.

Wilhite, D. A., 1987: Drought in the Great Plains: A Bibliography. Nebraska Agricultural Experimental Station Misc. Publ. 39, University of Nebraska, $75 \mathrm{pp}$.

Williams, A. P., R. Seager, J. T. Abatzoglou, B. I. Cook, J. E. Smerdon, and E. R. Cook, 2015: Contribution of anthropogenic warming to California drought during 2012-2014. Geophys. Res. Lett., 42, 6819-6828, doi:10.1002/2015GL064924.

Woodhouse, C. A., and J. T. Overpeck, 1998: 2000 years of drought variability in the central United States. Bull. Amer. Meteor. Soc., 79, 2693-2714, doi:10.1175/1520-0477(1998)079<2693: YODVIT $>2.0 . \mathrm{CO} ; 2$.

Xia, Y., and Coauthors, 2012: Continental-scale water and energy flux analysis and validation for the North American Land Data Assimilation System Project Phase 2 (NLDAS-2): 1. Intercomparison and application of model products. J. Geophys. Res., 117, D03109, doi:10.1029/ 2011JD016048.

Yin, D., M. L. Roderick, G. Leech, F. Sun, and Y. Huang, 2014: The contribution of reduction in evaporative cooling to higher surface air temperatures during drought. Geophys. Res. Lett., 41, 7891-7897, doi:10.1002/2014GL062039.

Zhao, T., and A. Dai, 2015: The magnitude and causes of global drought changes in the twenty-first century under a lowmoderate emissions scenario. J. Climate, 28, 4490-4512, doi:10.1175/JCLI-D-14-00363.1. 